\title{
The Influence of In-Situ Clad Staining on the Corrosion of Zircaloy In PWR Water Environment
}

\author{
B. F. Kammenzind, K. L. Eklund and R. Bajaj
}

Bechtel-Bettis, Inc., P.O.Box 79, West Mifflin, PA 15122-0079

\section{Presented at the Thirteenth International Symposium on \\ Zirconium in the Nuclear Industry}

Anacy, France

June 11-14, 2001

\begin{abstract}
This report was prepared as an account of work sponsored by an agency of the United States Government. Neither the United States Government nor any agency thereof, nor any of their employees, nor any of their contractors, subcontractors or their employees, makes any warranty, express or implied, or assumes any legal liability or responsibility for the accuracy, completeness, or any third party's use or the results of such use of any information, apparatus, product, or process disclosed, or represents that its use would not infringe privately owned rights. Reference herein to any specific commercial product, process, or service by trade name, trademark, manufacturer, or otherwise, does not necessarily constitute or imply its endorsement, recommendation, or favoring by the United States Government or any agency thereof or its contractors or subcontractors. The views and opinions of authors expressed herein do not necessarily state or reflect those of the United States Government or any agency thereof.
\end{abstract}




\section{Introduction}

Zircaloy cladding tubes strain in-situ during service life in the corrosive environment of a Pressurized Water Reactor for a variety of reasons. First, the tube undergoes stress free growth due to the preferential alignment of irradiation induced vacancy loops on basal planes. Positive strains develop in the textured tubes along prism orientations while negative strains develop along basal orientations (Reference (a)). Second, early in life, free standing tubes will often shrink by creep in the diametrical direction under the external pressure of the water environment, but potentially grow later in life in the diametrical direction once the expanding fuel pellet contacts the cladding inner wall (Reference (b)). Finally, the Zircaloy cladding absorbs hydrogen as a by product of the corrosion reaction (Reference (c)). Once above the solubility limit in Zircaloy, the hydride precipitates as zirconium hydride (References (c) through (j)). Both hydrogen in solid solution and precipitated as Zirconium hydride cause a volume expansion of the Zircaloy metal (Reference $(k))$.

Few studies are reported on that have investigated the influence that in-situ clad straining has on corrosion of Zircaloy. If Zircaloy corrosion rates are governed by diffusion of anions through a thin passivating boundary layer at the oxide-to-metal interface (References (I) through (n)), in-situ straining of the cladding could accelerate the corrosion process by prematurely breaking that passivating oxide boundary layer. References (o) through (q) investigated the influence that an applied tensile stress has on the corrosion resistance of Zircaloy. Knights and Perkins, Reference (o)), 
B-T-3352

Page 3 of 46

reported that the applied tensile stress increased corrosion rates above a critical stress level in $400^{\circ} \mathrm{C}$ and $475^{\circ} \mathrm{C}$ steam, but not at lower temperatures nor in dry oxygen environments. This latter observation suggested that hydrogen either in the oxide or at the oxide-to-metal interface is involved in the observed stress effect. Kim et al. (Reference (p)) and Kim and Kim (Reference (q)) more recently investigated the influence that an applied hoop stress has on the corrosion resistance of Zircaloy tubes in a $400^{\circ} \mathrm{C}$ steam and in a $350^{\circ} \mathrm{C}$ concentrated lithia water environment. Both of these studies found the applied tensile hoop stress to have no effect on cladding corrosion rates in the $400^{\circ} \mathrm{C}$ steam environment but to have accelerated corrosion in the lithiated water environment. In both cases, the corrosion acceleration in the lithiated water environment was attributed to the accumulation of the increased hydrogen picked up in the lithiated environment into the tensile regions of the test specimen. Dense hydride rims have been shown, independent of clad strain, to accelerate the corrosion of Zirconium alloys (References (r) and (s)), suggesting that the primary effect of applied stresses on the corrosion of Zircaloy in the above studies is through the accumulation of hydrogen at the oxide-to-metal interface and not through a direct mechanical breakdown of the passivating boundary layer.

To further investigate the potential role of in-situ clad straining (or stress) on Zircaloy corrosion rates, two experimental studies were performed. First, several samples that were irradiated with and without an applied stress were destructively examined for the extent of corrosion occurring in strained and nonstrained regions of the test samples. The extent of corrosion was determined, posttest, by metallographic 
examination. Second, the corrosion process was monitored in-situ using electrochemical impedance spectroscopy on samples exposed out-of-reactor with and without an applied stress. Post test, these autoclave samples were also metallographically examined.

\section{Experimental Procedure}

In-Reactor Stressed Samples

Three Zircaloy-4 creep samples exposed in the Advanced Test Reactor (ATR) were metallographically examined to determine oxide thicknesses. All three samples were machined from hot-rolled plate product with an annealing parameter greater than $\sim 1$ $\times 10^{-18} \mathrm{hrs}$ where the annealing parameter (Reference $(\mathrm{gg})$ is defined as:

$$
\begin{aligned}
& \qquad A=t_{i} \exp \left(40,000 / T_{i}\right) \\
& t_{i}=\text { the time of annealing step } i \text { in hrs, and } \\
& T_{i}=\text { the temperature of annealing step } i \text { in degrees Kelvin. }
\end{aligned}
$$

Following machining, all samples were pickled in a standard $\mathrm{HF}-\mathrm{HNO}_{3}-\mathrm{H}_{2} \mathrm{O}$ solution. All three of these samples were loaded in-situ in the ATR environment by a bellows assembly producing a $300-\mathrm{lb}$ tensile load on the test samples under system pressure. Two of the samples were of a double dumbbell design (Figure (1)) producing a 10,000-psi and a 25,000-psi tensile stress in the two gage sections. One of the samples was a single dumbbell design producing a 15,000 psi stress in the gage section (Figure (2)). Each sample also had a section with approximately an order of 
magnitude less stress. All three samples were exposed in the ATR to temperatures of $\sim 293^{\circ} \mathrm{C}$ and neutron fluxes of $\sim 1.0$ to $1.5 \times 10^{14}$ neutrons $/ \mathrm{cm}^{2}$-sec in deionized, degassed water with a hydrogen overpressure of $30 \mathrm{cc} \mathrm{H} / \mathrm{kg}$ water to $60 \mathrm{cc} \mathrm{H}_{2} / \mathrm{kg}$ water and a room temperature $\mathrm{pH}$ of 10.0 to 10.3 . The strain histories experienced by these three samples are given in Figure (3).

The three creep samples were sectioned to provide metallographic samples in both the highly stressed gage sections of the samples and in the lowly stressed regions of the samples. The metallographic sections from each sample were mounted in cross section in epoxy, ground $\sim 0.030$ inches, and polished with a focus on maintaining good edge retention of the surface corrosion films. Representative micrographs were taken at several positions around the circumference of each of the test specimens at 500X. The micrographs were scanned into image analysis software (approximately 6 micrographs per cross section) and thickness measurements of the corrosion film were made at 10 random locations across each micrograph. Averages and standard deviations were calculated from the approximately sixty measurements obtained at each cross section examined.

\section{Autoclave Testing}

Two autoclave tests were conducted, each with two Zircaloy-4 uniaxial tensile specimens machined from hot-rolled plate product with an annealing parameter of greater than $1 \times 10^{-18} \mathrm{hrs}$. Following machining, both samples were pickled in a 
standard $\mathrm{HF}-\mathrm{HNO}_{3}-\mathrm{H}_{2} \mathrm{O}$ solution. One of the tensile samples in each test was placed in the load train of the autoclave; the second tensile sample hung freely in the autoclave at the same approximate axial elevation as the loaded sample. Two rounds of autoclave testing were performed. EIS information was obtained form the nonstrained electrode only in the first round of testing, while EIS information was obtained form both the strained and the nonstrained electrode in round 2 testing. The load train of the autoclave is connected to an electric actuator capable of maintaining a constant extension rate down to 0.000001 inches per minute.

$\mathrm{A} \mathrm{Ag/AgCl} \mathrm{external} \mathrm{pressure} \mathrm{balanced} \mathrm{reference} \mathrm{electrode} \mathrm{(EPBRE),} \mathrm{a} \mathrm{Pt} \mathrm{reference}$ electrode, and two Pt counter electrodes also were included in the autoclave. The EPBRE provides a reference potential that is insensitive to redox species in solution. Abrupt changes in the potential of the Pt electrodes, or even the autoclave, relative to the EPBRE thus aided in troubleshooting any gross chemical changes in the electrolyte. The Pt reference electrode, which is far more stable than the EPBRE, and the Pt counter electrodes were used for the characterization of the Zircaloy samples by impedance spectroscopy throughout the course of the test.

The test was conducted at a temperature of $338^{\circ} \mathrm{C}$ in deionized degassed water with a $30 \mathrm{cc} \mathrm{H}_{2} / \mathrm{kg}$ water to $60 \mathrm{cc} \mathrm{H}_{2} / \mathrm{kg}$ water hydrogen concentration and a room temperature $\mathrm{pH}$ of 10.0 to 10.3. During the course of the high-temperature exposure, the Zircaloy-4 sample in the autoclave load train was strained at a rate of 0.0025 inches per day or 0.05 percent per day. The Zircaloy 4 sample hanging free was not 
B-T-3352

Page 7 of 46

strained. Several test parameters were recorded during the corrosion test at two minute intervals. These include: 1) autoclave temperature, pressure and flow rate, 2) corrosion potentials of the test samples, the grips, and the $\mathrm{Ag} / \mathrm{AgCl}$ reference electrode with respect to the Pt electrode, and 3) the load on the straining Zircaloy test sample and the extension of the sample as measured by two LVDTs attached to the pull rod of the load train. In addition, the hydrogen concentration, oxygen concentration and $\mathrm{pH}$ of the water were sampled three times per week, and the cation and the anion contents of the water were analyzed once per week.

At the beginning of the test, and in $\sim 30$ day intervals thereafter, the temperature of the autoclave was reduced to $260^{\circ} \mathrm{C}$, the load on the straining electrode was relaxed, and impedance scans of the Zircaloy samples were collected. Impedance scans were obtained only from the nonstrained electrode in the first round of testing and from both the strained and the nonstrained electrode in the second round of testing. The impedance scans were gathered over a frequency range of $5000 \mathrm{~Hz}$ to $10^{-4} \mathrm{~Hz}$, taking on the order of three days to gather each scan. The autoclave temperature was reduced to $260^{\circ} \mathrm{C}$ to increase the electrical conductivity of the simulated pressurized water reactor environment. Figure 4 summarizes a representative temperature exposure history from a portion of the test. The first autoclave test was conducted for a total period of eight approximately 30 -day cycles at the $338^{\circ} \mathrm{C}$ exposure temperature. During the periods at $338^{\circ} \mathrm{C}$, the specimens in the load train of the autoclave were strained. During the periods at $260^{\circ} \mathrm{C}$ the loads on the straining samples were released. A representative load history and strain history 
from a portion of the test is summarized in Figure 5. The straining test sample in the first of the autoclave experiments strained a total of $\sim 12$ percent, and eight sets of impedance scans were obtained on the freely hanging sample. After corrosion testing, the samples from the first autoclave experiment were metallographically examined to determine corrosion thickness and hydrogen concentration. Since round 2 testing is continuing, only EIS data are available from Round 2, representing the majority of the anticipated pretransition period.

\section{Experimental Results}

Metallographic Measurements of In-Reactor Samples

Examples of the corrosion film observed on the ATR creep samples are provided in Figure (6). In general, the corrosion films were uniform in thickness, dense and adherent. The metallographic measurements of corrosion film thickness obtained from the ATR stressed samples are illustrated in Figure 7. Each of the metallographic measurements made around the circumference of the samples is plotted. The $y$-axis of Figure 7 is corrosion film thickness in mils while the $x$-axis is just a counter denoting each measurement. The data are labeled on Figure 7 as non-stressed, $10 \mathrm{ksi}, 15 \mathrm{ksi}$, and $25 \mathrm{ksi}$ to denote the stress level of the sample section from which the measurements were made. Figure 7 shows a great deal of overlap among the data sets from a single specimen, and no real strong trend for an effect of either the applied stress or resulting strain on the corrosion of the Zircaloy. There is no statistically significant difference among the data sets obtained from any 
one set of creep samples as determined by a student $t$ test of the means of the measured film thickness.

\section{Autoclave Test Sample Metallographic Measurements}

The visual appearance of the test samples as removed from the autoclave is illustrated in Figure 8. The gage section of the stressed (strained) electrode appeared lighter in color than the nonstressed (nonstrained) electrode. Representative micrographs of the corrosion film formed on the autoclave test samples are shown in Figure 9. Under the autoclave test conditions there now is a clear difference between the film forming on the strained electrode and that forming on the nonstrained electrode. The strained electrode film is noticeably cracked and thicker than the film forming on the nonstrained electrode. Metallography revealed both samples to have low hydrogen concentrations and few hydrides. The hydrides present were uniformly distributed through the material. Metallographic measurements of the thickness of the two corrosion films are plotted on Figure 10. The strained electrode has a thicker film than the nonstrained electrode and the difference is statistically significant.

\section{Autoclave test Sample Electrochemical Measurements}

Figures $11 \mathrm{a}$ and $11 \mathrm{~b}$ show the times of EIS testing relative to the estimated oxidation kinetics in autoclave at $640^{\circ} \mathrm{F}$ using relationships generated by Hillner (Reference 
hh). The final average oxide film thickness as metallographically measured on the round 1 nonstrained sample (Figure 10) is in reasonable agreement with the kinetics depicted in Figure 11a. Round 2 testing has not yet been metallographically examined but all EIS data reported here-in remained within the expected pretransition period for the nonstrained sample. The time that each sample spent at $260^{\circ} \mathrm{C}$ during EIS testing was not included in the estimates shown Figure 11.

The EIS results from the nonstrained sample in Round 1 testing are given in Figures $12 \mathrm{a}$ and $12 \mathrm{~b}$. As oxidation progresses, several trends are apparent in the data. First, the low-frequency impedance modulus increases with exposure time. Second, the absolute magnitude of the maximum phase angle increases and its location shifts to higher frequencies with increasing exposure time. Finally, there is a transition in the spectrum from a single time constant to a dual time constant. The dual time constant nature of the response is faint at 147 and 181 days, but becomes prominent after 214 days of exposure. The emergence of a second distinct time constant approximately coincides with the anticipated transition point. Further, the nature of the impedance spectra remain fairly constant after 214 days, i.e., into the posttransition region.

Since many EIS spectra in the open literature were obtained at room temperature rather than in-situ at the corrosion temperature, a final EIS spectrum of the free sample was obtained at the end of Round 1 testing, with the autoclave at room temperature and a pressure of 2200 psi. As expected, the low-frequency impedance increased by well over an order of magnitude at the lower temperature. In addition 
the dual time constant nature of the spectra was more prominent with a decrease in the frequency of the low-frequency phase-angle minima and an increase in the magnitude of the phase angles.

The measured impedance characteristics of the corrosion films forming on the strained and nonstrained electrodes as a function of exposure time in Round 2 autoclave testing are shown in Figures 13 through 15. In Figure 13, the impedance behavior of the nonstrained electrode as a function of time is provided, while Figure 14 illustrates the impedance behavior of the strained electrode at similar times, taken with the load removed during the EIS measurements. The low-frequency impedance modulus of the nonstrained electrode quickly increases, then levels off, consistent with the initial stages of oxidation. Also, the single time-constant behavior develops into a dual time constant system as the exposure times increase. The behavior of the nonstrained sample in Round 2 testing compares well to that of the sample in Round 1 testing.

By contrast, there are several effects attributable to the application of a strain when comparing Figures 12 and 13 to Figure 14. First, at all times, the low frequency impedance modulus is approximately 3 to 6 times lower for the strained sample than for the companion nonstrained sample in Round 2 testing. As in the nonstrained samples, the low-frequency impedance modulus for the strained samples shows an initially rapid increase, then becomes nearly constant with further exposure up to 98 days. Second, the maximum in the absolute magnitude of the phase angle remains at 
lower frequencies and at smaller values than for the companion nonstrained sample. Third, the EIS measurements on the strained electrode again show a transition from a single to a double time constant nature, but the evolution appears delayed from the nonstrained sample, i.e. the results for 120 days of exposure more closely resemble the results of the nonstrained electrode at 60 days of exposure. Finally, the highfrequency modulus limit of both the strained and nonstrained samples at the same exposure time in Round-2 tests coincided well with one another, indicating that the electrical isolation to the autoclave was sufficient.

To gain some further insight as to the effect of the applied load, several EIS spectra were taken at $260^{\circ} \mathrm{C}$, either with the load applied or with the samples actively straining. Results are shown in Figure 15. Comparing like exposure times in Figures 14 and 15, it appears that the load induces the appearance of a much more distinct dual time constant response. The-low frequency impedance modulus limit also decreases by half an order of magnitude (now nearly a full order of magnitude lower than in the nonstrained cases in Figure 13) and the absolute magnitude of the phase angle decreases from that observed when nonstrained. As in all other results, the high-frequency impedance limit still corresponds to a reasonable value for the solution resistance. Therefore, the electrical isolation to the load train was not breached upon application of the load. While it is difficult to discern the highfrequency time-constant behavior in Figure 14, it appears to be centered near 100 Hz. The application of the load in Figure 15 does not appear to affect this high frequency region. However, there is a strong influence of the load on the low 
frequency response, shifting the peak phase-angle frequency from near $1 \mathrm{~Hz}$ to approximately $0.001 \mathrm{~Hz}$. As discussed in the next section, analyses of these spectrum in terms of analogue electric circuits provides insight into the possible physical significance of these trends.

\section{Discussion}

\section{Autoclave Test Samples}

An effect of in-situ clad straining on the corrosion kinetics of Zircaloy is readily observed from the autoclave test data. The posttest metallographic data show an acceleration in the corrosion of the strained sample in Round 1 testing. The acceleration in this case can not be attributed to high hydrogen concentrations accumulated at the oxide-to-metal interface, which was the case in References (k) and (I). The electrochemical impedance data illustrated above suggest that the straining is having an effect on the properties of the surface corrosion film. In the EIS testing, the strain reduces the magnitude of the impedance modulus and the magnitude and frequency of the maximum phase shift. These effects are illustrated further by analyzing the impedance data in terms of analogue electric circuits. The corrosion of Zircaloy-4 involves the growth of a passive film on the metal surface. Analogue circuits for the growth of passive films on metal surfaces were developed for Zircaloy by other investigators (References (t) through (v)) and for other alloys (References (w) and (z)). Among those developed for other alloys, the most 
applicable to Zircaloy were judged those developed to describe the behavior of anodized aluminum that has a thin protective amorphous oxide near the metal-tooxide interface and a thick porous outer oxide (References $(x),(y)$, and $(z))$. These analog circuits were used as the starting point for the analysis of the data of Figures 12 and 15 . The fitting of the impedance of the analogue circuit to the electrochemical data was done using commercially available software. Three criteria were used to obtain a best-fit description of the data; 1) the statistical goodness of the fit to the data, 2) the simplicity of the circuit, and 3) the ability to relate circuit components to physical processes. Using these criteria, and the way in which the spectra change from having one time constant to having two distinct time constants, the circuits depicted in Figure 16 were chosen. Essentially, these are simple parallel RC circuits (single and double) in series with the solution resistance. However, the capacitive component in each circuit is not a simple capacitor but a constant-phase element. Good fits to the EIS data could not be obtained with simple capacitors rather than a constant-phase element. Constant-phase elements are leaky capacitors, i.e.; they have a distribution of time constants rather than a single time constant, with an impedance governed by the relationships

$$
\begin{aligned}
& Z_{C P E}=A(j \omega)^{-\alpha} \\
& A=1 / C, j=\sqrt{-1}
\end{aligned}
$$


where $\alpha$ varies between 0 and unity, with unity representing ideal capacitance. The double RC circuit in Figure 16 is essentially the same circuit chosen by Barberis in Reference (v).

The evolution of the dual RC circuit parameter fits with time are summarized for the nonstrained sample in Round 1 testing in Table1, for the nonstrained sample in Round 2 testing in Table 2, and for the strained sample in Round 2 testing in Table 3. Often, the data of Figures 12 through 15 show a sharp increase in phase angle at frequencies greater than $1000 \mathrm{~Hz}$. This response is believed to be an artifact, due to inhomogeneous current and potential distributions in the low-conductivity electrolyte. As a result, the fitting calculations often did not utilize data above $1000 \mathrm{~Hz}$. The solid lines in Figures 12 through15 show the fit of the double RC circuit model to the data.

From Tables 1 and 2, it is apparent that the two RC circuit components describing the nonstrained electrode have a different character from the RC circuit components for the strained electrodes. The lower frequency component in the nonstrained electrode is more resistive in nature. Its resistance increases somewhat with time, while its capacitance decreases with time. The second-higher-frequency component is more capacitive in nature. Its resistance is always significantly less than the resistance of the lower-frequency component. As may be expected, Tables 1 and 2 illustrate that the forced fit of the early-oxidation-time data to the dual RC circuit often contains substantial error in all values pertaining to the second high frequency $\mathrm{RC}$ component. This is a mathematical representation of what was noted graphically in the previous 
section: in the early stages of oxidation the data appears to have only one time constant, and if there is a separate high frequency time-constant "peak" at this time, its features are obscured by the low-frequency data. As the oxidation time in pretransition progresses, the relative errors in the second, high-frequency RC component values decrease. By the time the oxidation time has passed the expected transition in the corrosion kinetics, the high-frequency parameter errors are small. This observation suggests that some dual layer character is developing in the corrosion film even during the pretransition period. As a final check on the fitted values, the spectra from initial oxidation in Round 2 testing were fit to a single $\mathrm{RC}$ circuit, as summarized in Table 4. As expected, the results compare well to the lowfrequency values of the dual RC Circuit.

Low-magnification metallography of pretransition corrosion films found them to be a tenacious near-monolithic layers. Higher-magnification investigations with electron microscopy showed that much of the pretransition corrosion films consisted of nanometer-sized columnar grains with very fine porosity along the grain boundaries of the columnar grains (Figure (17)). The degree to which the intergranular porosity was interconnected could not be determined from the microscopy. Very near the oxide metal interface a second film microstructure often was observed, sometimes with a differing grain structure, but always with less porosity than was observed through the rest of the pretransition corrosion film. The developing dual character of the EIS response as corrosion time in pretransition progressed is interpreted to relate to these two regions in the pretransition corrosion film, the low frequency response to 
the inner dense layer and the higher frequency response to the outer more porous region.

Table 3 illustrates the same general trends for the strained electrode when the impedance is measured with no load applied. However the resistance of the low-frequency component is less and the high-frequency component developed slower than for the nonstrained sample. The application of a load in-situ while the EIS spectra were obtained further reduced the low-frequency component resistance and increased its capacitive nature. The load did not appear to significantly alter the high-frequency RC circuit parameters. These trends provide some electrochemical evidence of the origin of the higher-corrosion rate of the strained sample metallographically observed in Round 1 testing. Physically, the EIS is interpreted to mean that the low resistance of the sample to oxidation via the application of a load is due to through-thickness cracking of the "outer" (high frequency) region of the film throughout the gage section of the specimen. These cracks increase permeability to the oxidizing water environment. Likely through cracking, the load also decreases the effective resistance of the inner (low-frequency) region of the film, which also allows faster oxidation of the sample. The fact that the corrosion film properties are impacted by the straining from the very beginning of the test indicates that it is not the accumulated strain that is the factor but the instantaneous conditions to which the sample is subjected, either due to stress or strain rate. 
In-Reactor Stressed Samples

Unlike the autoclave samples, no statistically significant effect of stress, or strain rate was observed on the final corrosion film thickness of the in-reactor stressed samples. In both cases the samples experienced several percent strain over the normal duration of the pretransition and early transitory corrosion kinetics. Several potential differing factors between the in-reactor stressed sample conditions and the autoclave conditions include: 1) the approximate order of magnitude slower creep rate experienced by the $293^{\circ} \mathrm{C}$ in-reactor samples $\left(\sim 5 \times 10^{-5}\right.$ per day), as opposed to the $338^{\circ} \mathrm{C}$ autoclave samples $\left(5 \times 10^{-4}\right.$ per day), 2$)$ the lower average stress experienced by the in-reactor samples $(<25,000 \mathrm{psi})$ versus the autoclave sample $(>30,000 \mathrm{psi})$, and 3) the irradiation environment.

The imposed strain rate on the underling metal and the corrosion film is judged to be the critical factor in these experiments, and not the applied stress, for two reasons. First, the inner regions of the corrosion film are inherently subjected to a very large compressive stress (several hundred thousand psi) as a result of the volume expansion to form the oxide from the metal, (Reference (aa)). The application of a stress of only on the order of 10 percent of that level, without producing straining of the base metal, is judged inconsequential. Second, the impedance data of the autoclave sample indicated an effect on the straining specimen from the very beginning of test, even when the applied stress was lower than 25,000 psi. This same 
applied stress, but at a lower strain rate of the base metal produced no statistically significant effect in-reactor.

The creep rates of all the test samples examined versus the acceleration in corrosion rates are plotted in Figure 18. As discussed earlier, the observed effect at creep rates below 0.01 percent per day are not statistically significant. However, a trend exists even in this region for increasing corrosion with increasing strain rate. The irradiation environment may be a contributing factor in minimizing the affect of an applied strain in the in-reactor samples in that the Zircaloy corrosion film may be able to better accommodate plastic deformation at very low creep rates. This accommodation may be due to the excess point defects produced in the neutron irradiation field. The ability of a Zircaloy corrosion film to "creep" under load has not been studied extensively but is likely to increase with increasing temperature and fast flux. This would suggest that there might exist a threshold creep rate, which is an increasing function of both temperature and neutron flux, below which corrosion will not be accelerated.

Impact of Clad Straining on Zircaloy Cladding Corrosion Rates

As discussed in the introduction, Zircaloy corrosion films are subjected to several sources of stress and strain during service. The mere fact that the film is growing on the external surface of a cylindrical fuel rod is one source. The outer diameter of the fuel rod expands slightly as the film grows due to the volume expansion in forming 
the oxide. However, the circumferential strains produced in the growing corrosion film as a result of this expansion are only on the order of $\sim 5 \times 10^{-6}$ per day, well below strain levels at which any effect was seen in the subject experiments. The outer diameter of the fuel rod also potentially changes in response to the growing fuel pellets within it. The results reported herein indicate that, depending upon the expansion rate of the fuel element, this may be a factor in the corrosion performance of the cladding. However, using the late-in-life swelling data reported in Reference (b), late in life circumferential strain rates resulting from pellet-clad interactions are only on the order of $10^{-5}$ per day, which is in the range of the strain rate of the hereinreported in-reactor data where no statistically significant effect is observed. Thus, insitu straining of the cladding does not appear to be a factor in the significant late-inlife acceleration in cladding corrosion rate often reported for high burnup Zircaloy clad fuel elements.

However, even if the fuel element cladding is free standing during life, the ability of the corrosion film to accommodate strain may still be a very important parameter in the Zircaloy corrosion process. The oxide-to-metal interface is known not to be smooth but to develop a roughness with time (References (bb) through (dd)). This fine scale roughness is on the order of the corrosion film boundary layer thickness (microns) and adds another source for developing tensile and compressive strains as the film grows. Strains that can develop within the thin inner boundary layer as a result of the oxide film growing on the nonuniform surface are calculated (depending on the surface roughness and the corrosion rate) to be greater than $5 \times 10^{-4}$ per day 
in posttransition. This is greater than the strain rate applied to the autoclave specimen where an affect of the strain rate was observed. Therefore, strain rate of the growing corrosion film may be one factor in the increasing corrosion rate often observed in the posttransition period (References (ee) and (ff)).

\section{Summary and Conclusions}

1. Metallographic examinations of the corrosion films forming on uniaxially stressed samples show a trend for increasing corrosion rate with increasing applied strain rate. At strain rates below $5 \times 10^{-5}$ per day, the observed effect is not statistically significant.

2. The effect observed in these experiments is not a result of hydrogen accumulation at the oxide-to-metal interface in the tensile strained regions of the specimens since the effect was observed through in-situ impedance spectroscopy to be occurring from the very start of the corrosion process. In addition, the posttest hydrogen concentration of the specimens was observed to be low and uniformly distributed through the samples.

3. In-situ impedance spectroscopy data of the nonstrained electrode in an autoclave environment shows that the corrosion film has two components even in 
pretransition. The confidence in the existence of the second component increases as the pretransition corrosion period progresses and the corrosion kinetics passes the expected transition time.

4. In-situ impedance spectroscopy data of strained and nonstrained electrodes in an autoclave environment indicate that tensile straining of the base metal is causing a breakdown of the passivating layer forming on the specimen surface.

5. The dependence of the observed effect on the applied rate of strain may be a function of the ability of the Zircaloy corrosion film to plastically deform with the base metal.

6. Strain rates that are produced in the oxide film boundary layer as a result of the film growing on the external surface of a cylindrically shaped fuel rod appear slow enough to not be an accelerating factor in the Zircaloy corrosion process.

7. Average strain rates produced as a result of late in life swelling of the cladding contacting the fuel pellets also appear slow enough to not be an accelerating factor in the Zircaloy corrosion process.

8. The fine scale surface roughness that develops at the oxide-to-metal interface as the film thickens in posttransition produces local strain rates in the growing film boundary layer that may be sufficient to accelerate the corrosion process. This 
strain-rate effect may be one factor producing the upsweeping corrosion rates that are often seen in the posttransition period.

\section{References:}

a) Fidleris, V., "The Irradiation Creep and Growth Phenomena", Journal of Nuclear Materials, Vol. 159, 1988, pp. 22-42.

b) Hass, D., "Status of the Tribulation Programme", Proceedings of the International Topical Meeting on LWR Fuel Performance, April 17-20 1988, Williamsburg, Virginia

c) Kammenzind, B. F., et al., "Hydrogen Pickup and Redistribution in Alpha Annealed Zircaloy-4", Zirconium in the Nuclear Industry: Eleventh International Symposium, ASTM STP 1295, 1996, pp. 338-370.

d) Someno, M., "Determination of the Solubility and Diffusion Coefficient of

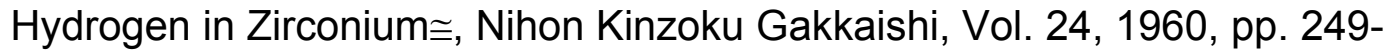
253.

e) Sawatzky, A., "The Diffusion and Solubility of Hydrogen in the Alpha Phase of Zircaloy-2", Journal of Nuclear Materials, Vol. 2 1960, pp. 62-68.

f) Mallet, M. W. and Albrecht, W. M., "Low Pressure Solubility and Diffusion of Hydrogen in Zirconium $\cong$, Journal of the Electrochemical Society, Vol. 104, 1957, pp. 142.

g) Slattery, G. F, "The Terminal Solubility of Hydrogen in Zirconium Alloys Between 30 and $400^{\circ} \mathrm{C} \cong$, Journal of the Institute of Metals, Vol. 95, 1967, pp. 43-47.

h) Kearns, J. J., "Terminal Solubility and Partitioning of Hydrogen in the Alpha

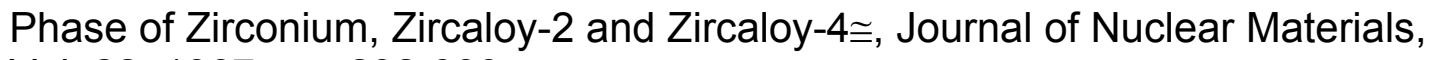
Vol. 22, 1967, pp. 292-303.

i) Erickson, W. H. and Hardie, D., "The Influence of Alloying Elements on the Terminal Solubility of Hydrogen in a Zirconium $\cong$, Journal of Nuclear Materials, Vol. 13, 1964, pp. 254-262.

j) Sawatzky, A. and Wilkins, B. J. S., "Hydrogen Solubility in Zirconium Alloys

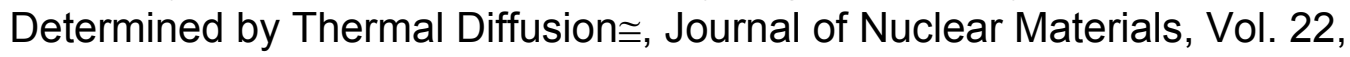
1967, pp. 304-310.

k) Kearns, J. J., et al, "Effect of Texture, Grain Size, and Cold Work on the

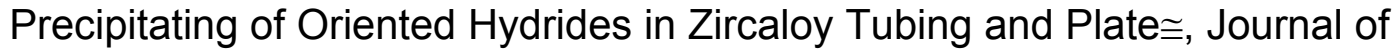
Nuclear Materials, Vol. 20, 1966, pp. 241-261.

I) "Waterside Corrosion of Zirconium Alloys in Nuclear Power Plants", IAEA TECDOC-996, January 1998. 
m) Beie, H., et al., "Examinations of the Corrosion Mechanism of Zirconium Alloys", Zirconium in the Nuclear Industry: Tenth International Symposium, ASTM STP 1245, 1994, pp. 615-643.

n) Wadman, B. "Mechanisms of Uniform Corrosion of Zirconium Alloys in Water and Steam", Chalmers University of Technology, 1993

o) Knights, C. F., and Perkins, R., "The Effect of Applied Tensile Stress on the Corrosion Behavior of Zircaloy 2 in Steam and Oxygen", Journal of Nuclear Materials, Vol. 36, 1970, pp. 180-188.

p) Young Suk Kim, Jae Soo Noh, Sang Chul Kwon, II Hyon Kuk, "Effect of Hoop Stress on Corrosion of Zircaloy-4 Cladding Tube", Journal of Nuclear Materials, Vol. 223, 1995, pp. 163-168.

q) Young Suk Kim, Sung Soo Kim, "The Cause of Accelerated Corrosion of Zircaloy-4 Cladding at High Burnup", 2000 ANS Topical Meeting on Fuel Performance, Parks City, Utah, April 2000

r) Blat, M., Noel, D., "Detrimental Role of Hydrogen on the Corrosion Rate of Zirconium Alloys $\cong$, Zirconium in the Nuclear Industry: Eleventh International Symposium, ASTM STP 1295, 1996, pp. 319-337.

s) Garde, A. M., "Enhancement of Aqueous Corrosion of Zircaloy-4 Due to Hydride Precipitation at the Metal Oxide Interface $\cong$, Zirconium in the Nuclear Industry: Ninth International Symposium, ASTM-STP 1132, 1991, pp. 566-594.

t) Gohr, H., et al., "Long Term In-Situ Corrosion Investigation of Zr Alloys in Simulated PWR Environments by Electrochemical Measurements", Zirconium in the Nuclear Industry: Eleventh International Symposium, ASTM-STP 1295, 1996, pp. 181-202.

u) Bossis, P., et al., "Multi-Scale Characterization of the Metal Oxide Interface of Zirconium Alloys", Zirconium in the Nuclear Industry: Twelfth International Symposium, ASTM-STP 1354, 2000, pp. 918-945.

v) Barberis,P., Frichet,A., "Characteriztion of Zircaloy-4 Oxide Layers by Impedance Spectroscopy", Journal of Nuclear Materials, Vol 273, 1999, pp. 182-191.

w) Macdonald, J. Ross, Impedance Spectroscopy, John Wiley and Sons, 1987.

x) Hoar, J. P., Wood, G. C., Electrochim. Acta, Vol. 7 pp. 333, 1962.

y) Hitzig, J., Juttner, K., Lorenz, W. J., Paatsch, W., J. Electrochem. Soc., Vol. 133, 5, pp. 887, 1986.

z) Mansfield, F., Kendig, M. W., J Electrochem. Soc., Vol. 135, 4, pp. 828, 1988.

aa) Garzarolli, F., et al., "Oxide Growth Mechanisms on Zirconium Alloys", Zirconium in the Nuclear Industry: Ninth International Symposium, ASTM-STP 1132, 1991, pp.395-415.

bb) Stehle, H., et al., "Characterization of ZrO2 Films Formed In-Reactor and Ex Reactor to Study the Factors Contributing to the In-Reactor Waterside 
Corrosion of Zircaloy", Zirconium in the Nuclear Industry: Sixth International Symposium, ASTM-STP 824, 1984, pp.483-506.

cc) Gebhardt, O., et al., "Investigation of In-Pile Grown Corrosion Films on Zirconium-Based Alloys", Zirconium in the Nuclear Industry: Eleventh International Symposium, ASTM-STP 1295, 1996, pp.218-241.

dd) Blank, H., et al., "Structural Analysis of Oxide Scales Grown on Zirconium Alloys in Autoclaves and in a PWR", Journal of Nuclear Materials, Vol. 188, 1992, pp. 273-279.

ee) Peters, H. R., "Improved Characterization of the Aqueous Corrosion Kinetics of Zircaloy-4", Zirconium in the Nuclear Industry: Sixth International Symposium, ASTM-STP 824, 1984, pp.507-518.

ff) Hillner, E. et al., "Long-Term Corrosion of Zircaloy Before and After Irradiation”, Journal of Nuclear Materials, Vol. 278, 2000, pp. 334-345.

gg) Charquet, D. et al., "Influence of Variations in Early Fabrication Steps on Corrosion, Mechanical Properties, and Structure of Zircaloy-4 Products", Zirconium in the Nuclear Industry, Seventh International Symposium, ASTM STP 939, American Society for Testing and Materials, 1987, pp. 431-447.

hh) Hillner, E., "Corrosion of Zirconium-Base Alloys - An Overview," in Zirconium in the Nuclear Industry, ASTM STP 633, A.L. Lowe, Jr. and G.W. Parry, Eds, ASTM, 1977, pp. 211-235 
ii)

Figure 1

Schematic of Double Gage Creep Sample

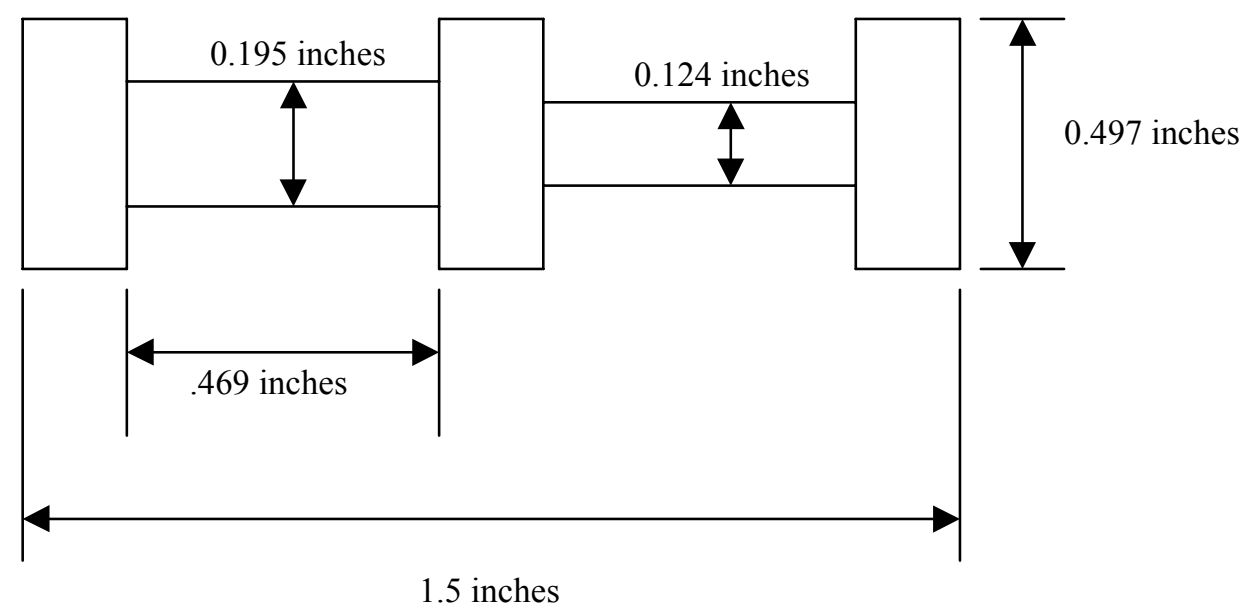

Figure 2

Schematic of Single Gage Creep Sample

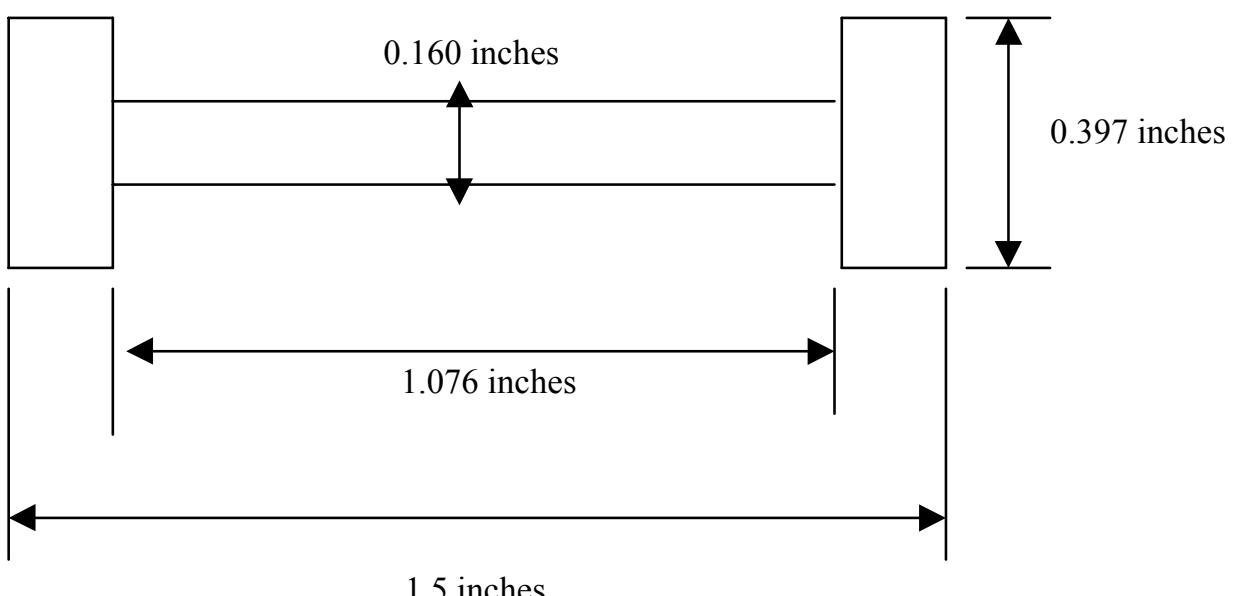


Figure 3

Strain Histories of ATR Creep Samples

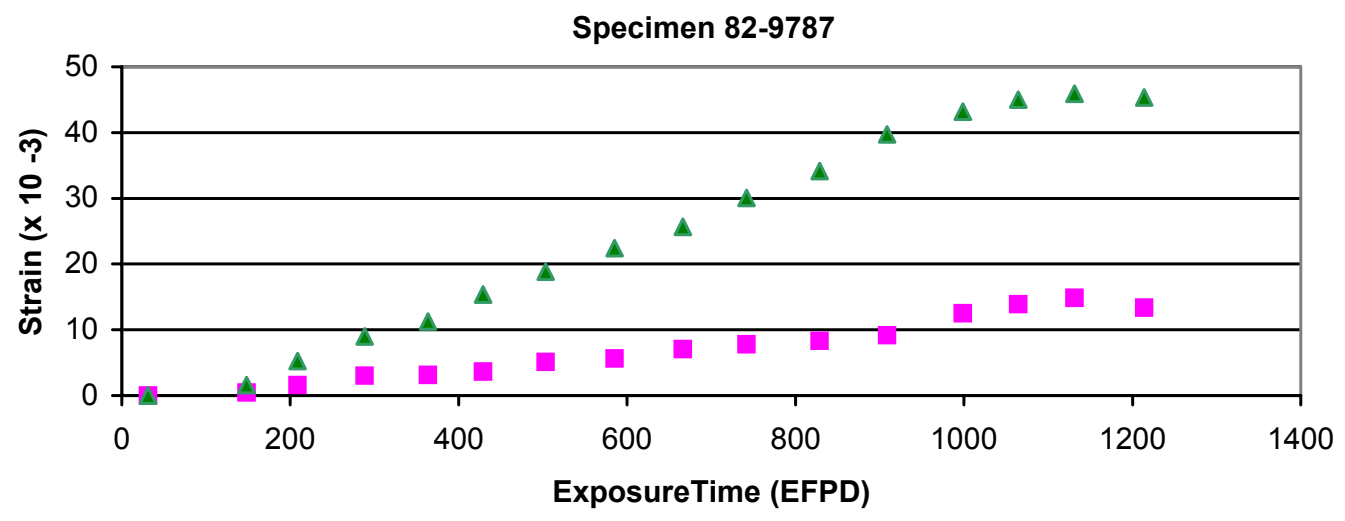

-10 ksi strain $\longleftarrow-25$ ksi strain

Specimen 99-0806

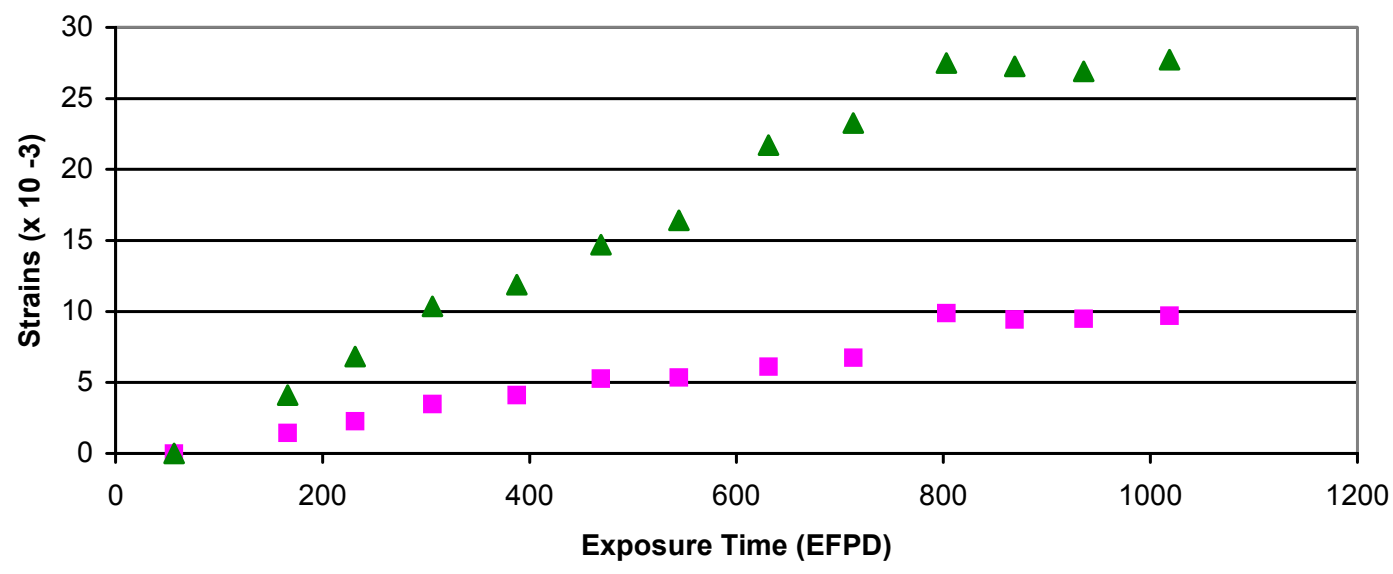

$-10 \mathrm{ksi}$ Strains $\rightarrow-25 \mathrm{ksi}$ Strains

Specimen 96-6435

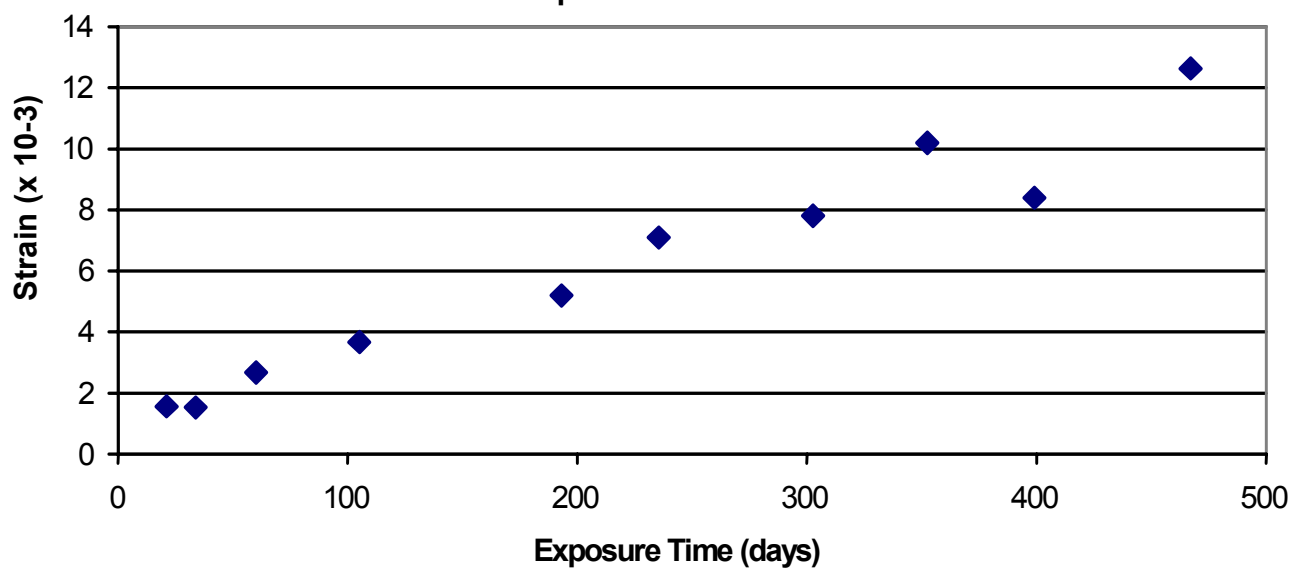

15 ksigetsejss 
Figure 4

Representative Temperature History for Autoclave Test Specimens

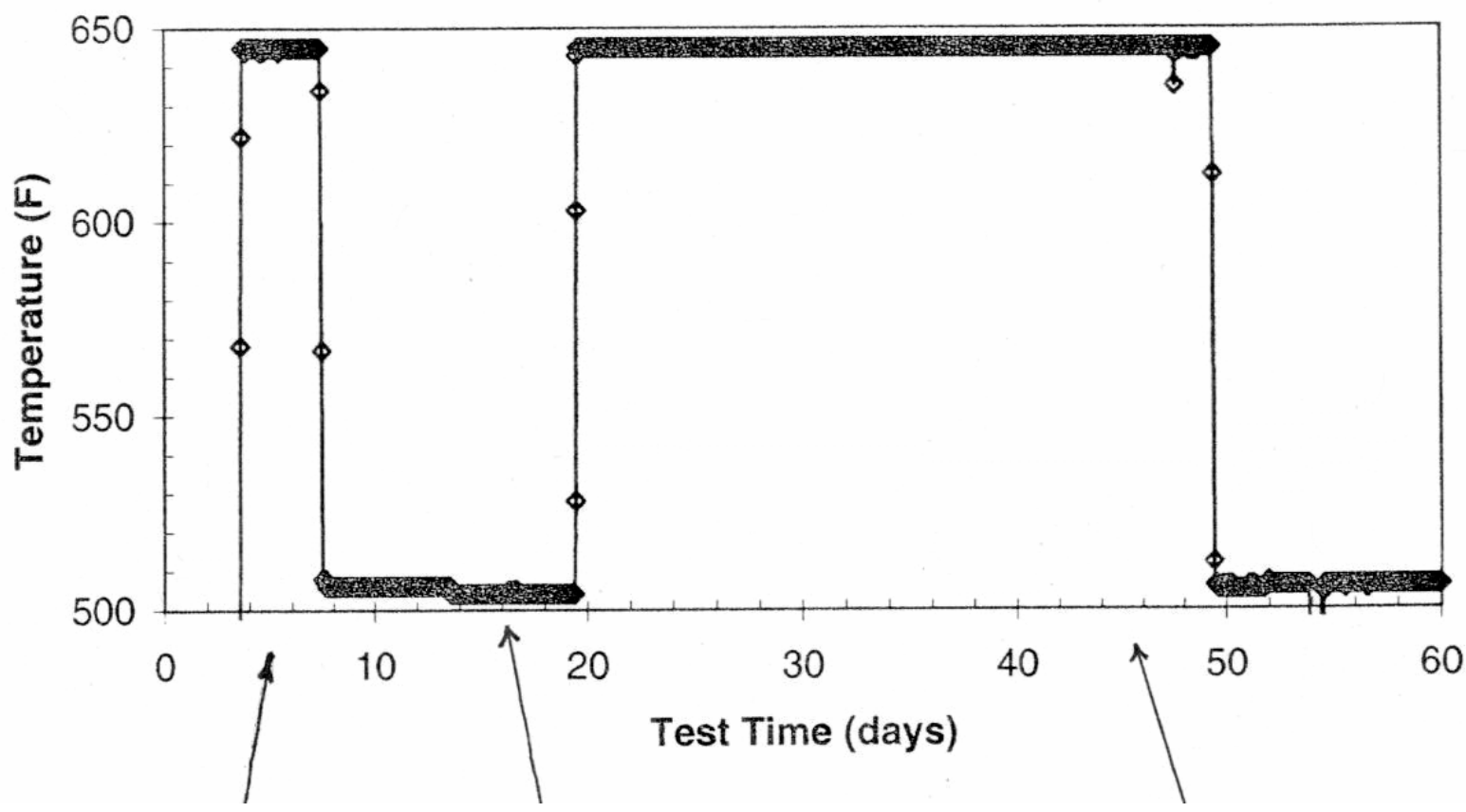

First 3 days of test at $640 \mathrm{~F}$
Period of Time Gathering Impedance Scans at $500 \mathrm{~F}$
Approximate 30 Day exposure time at $640 \mathrm{~F}$ 
Figure 5

Representative Load Strain History for Autoclave Test Specimens

(Specimen Straining Occurred only During Periods at $640 \mathrm{~F}$ )
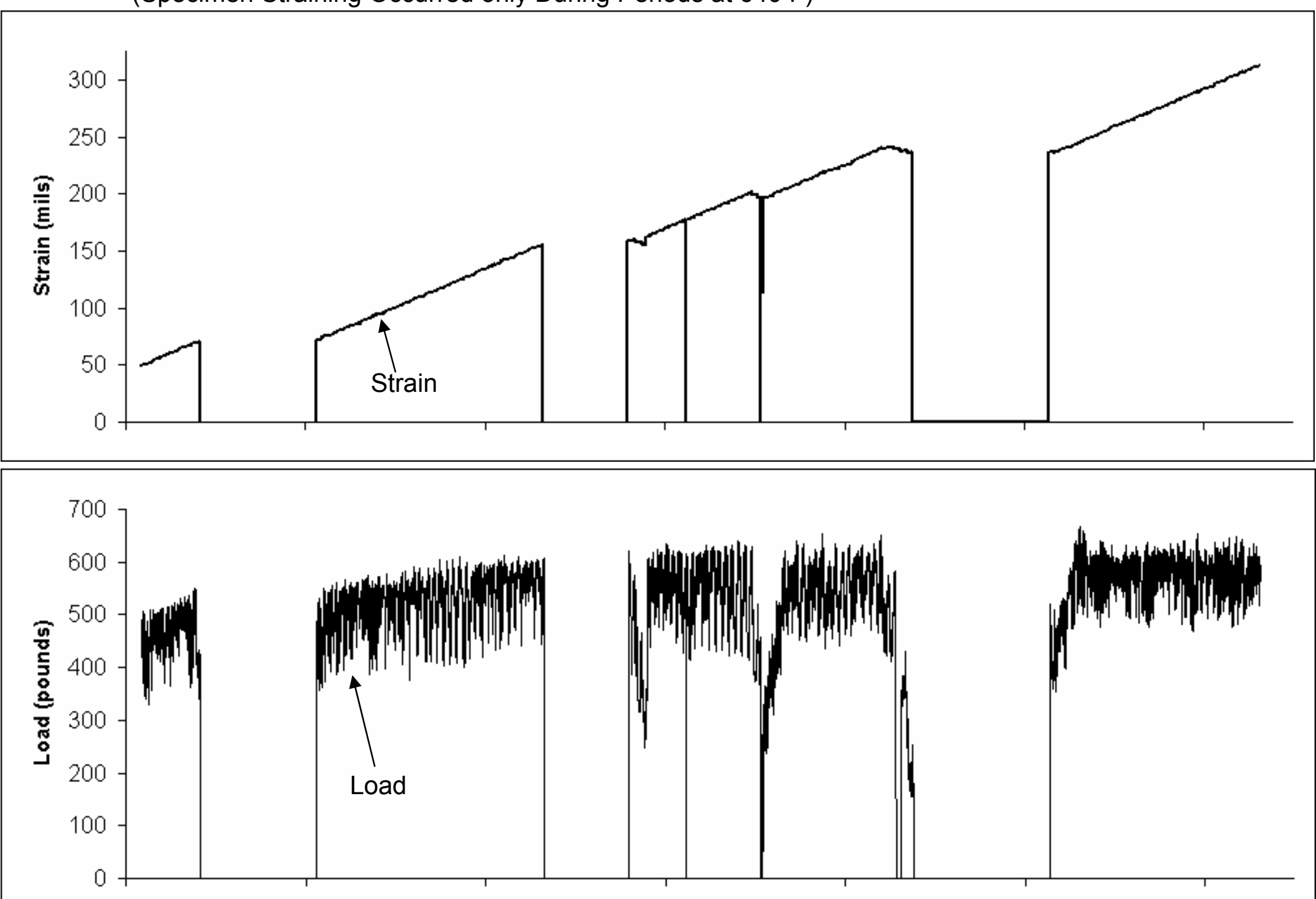
Figure 6

Representative Micrographs of ATR Creep Sample 99-0806

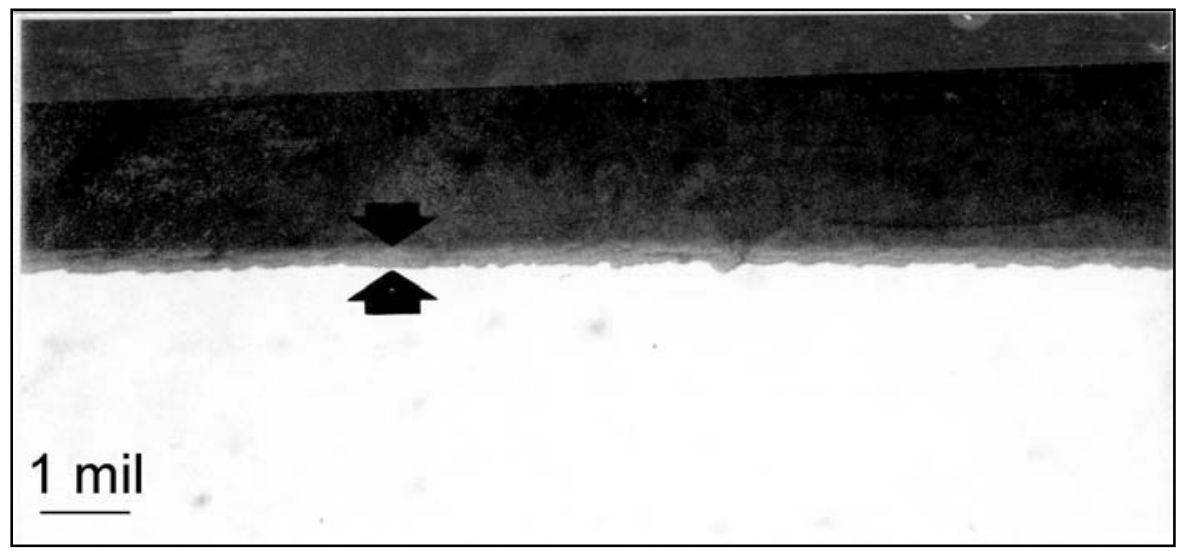

Non-Stressed

Section

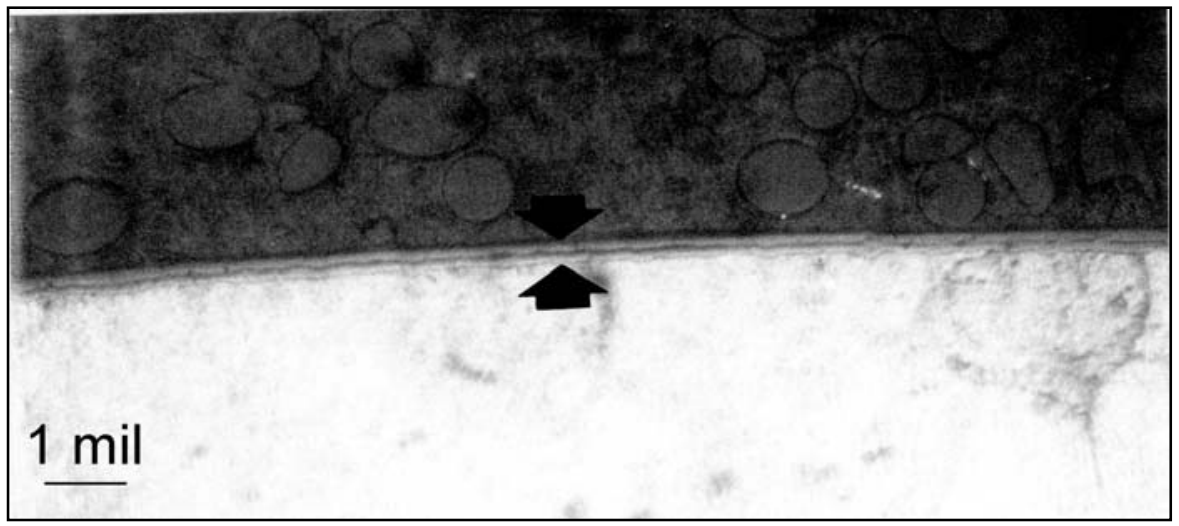

$10 \mathrm{KSI}$ Stressed Section

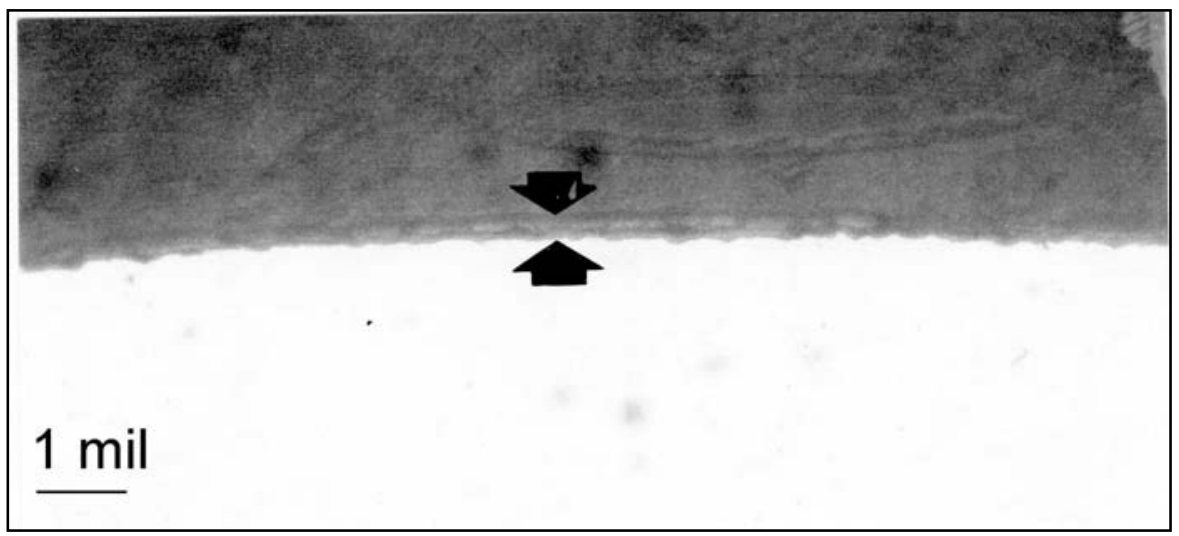

$25 \mathrm{KSI}$ Stressed Section 
Figure 7

Summary of Metallographic Measurements made on ATR Creep Samples

Summary of Measurements Made on Specimen 82-9787

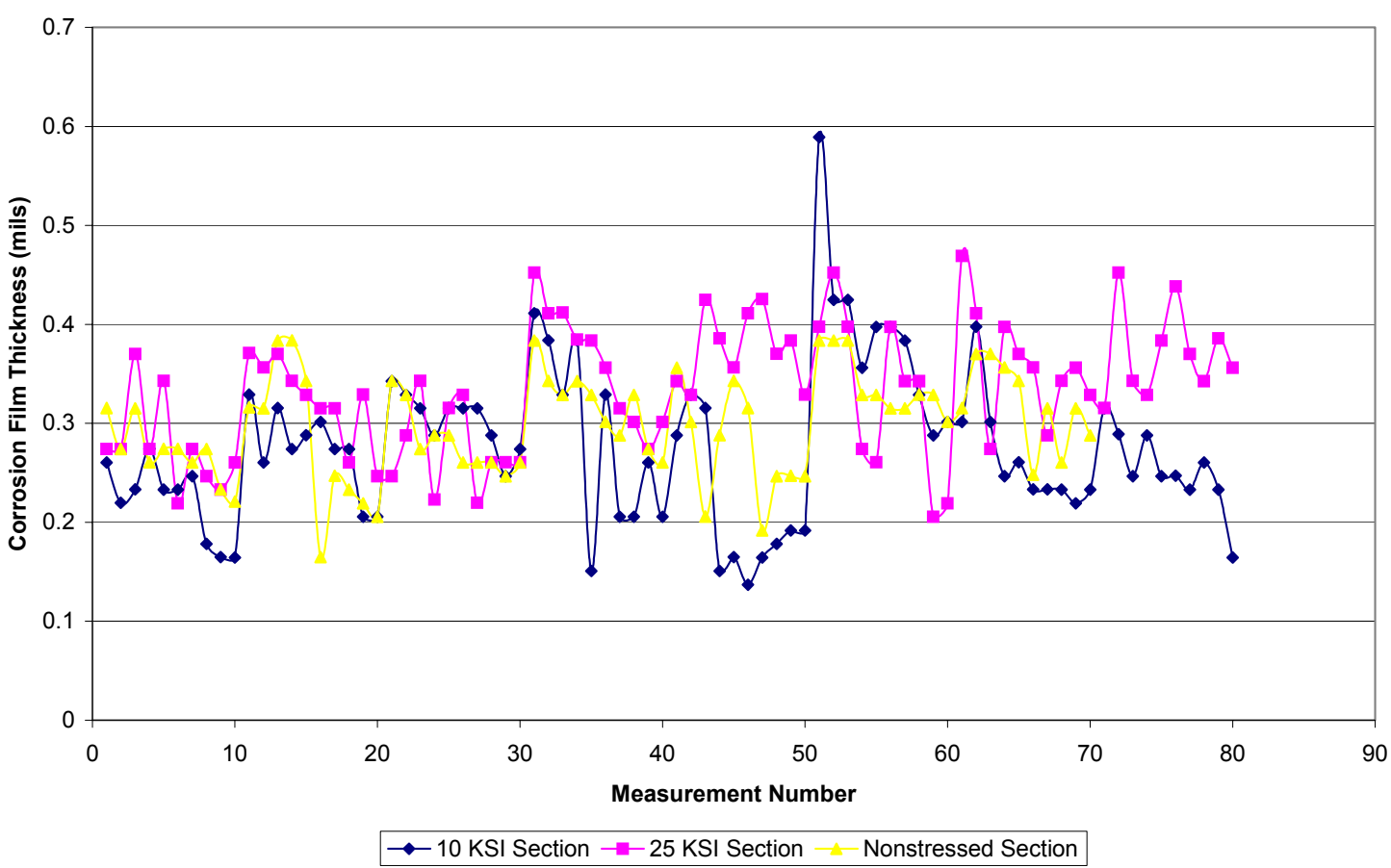

Summary of Measurements Made on Specimen 99-0806

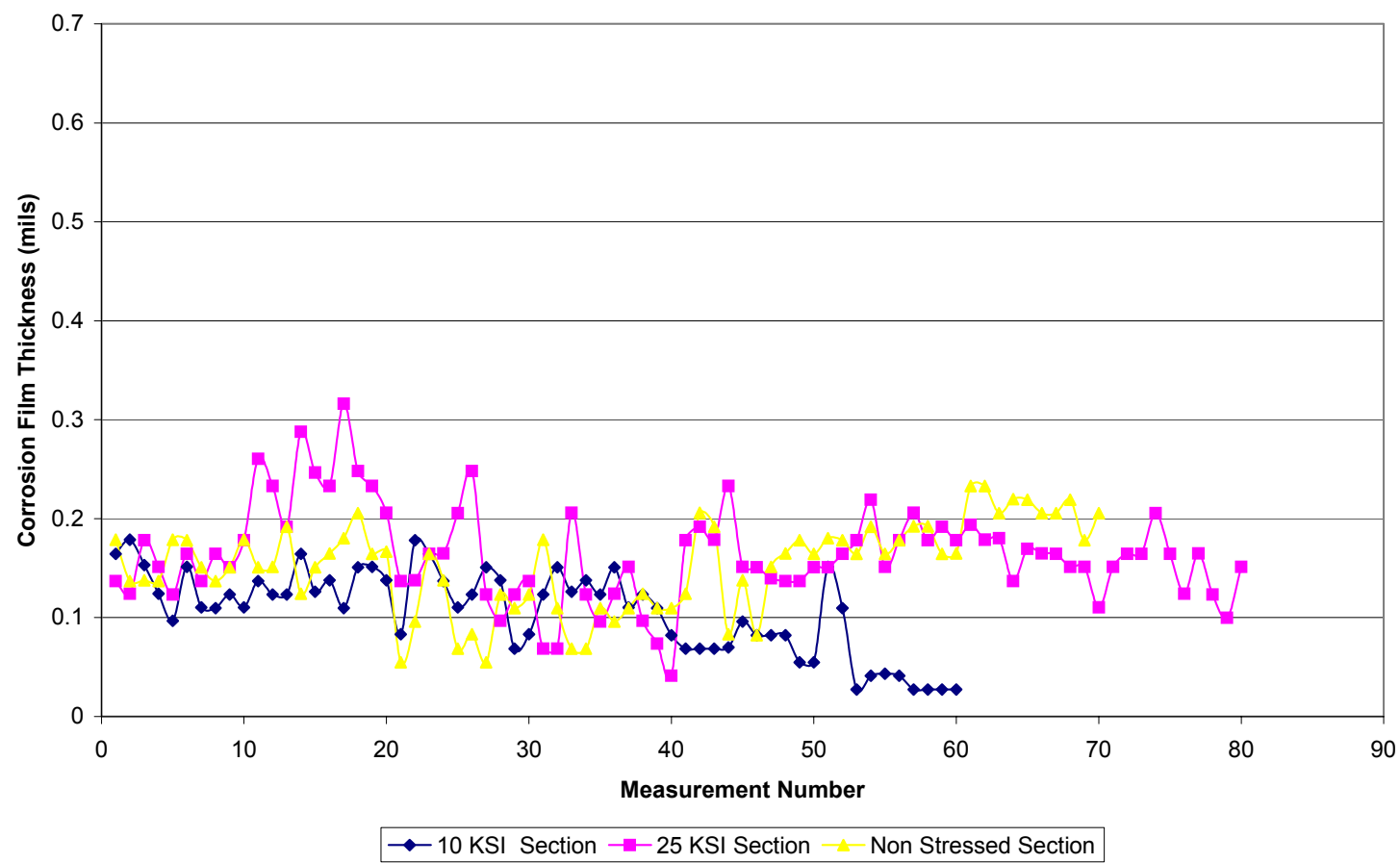


Figure 7 (Cont.)

Summary of Metallographic Measurements made on ATR Creep Samples

Summary of Measurements made on Specimen 99-6435

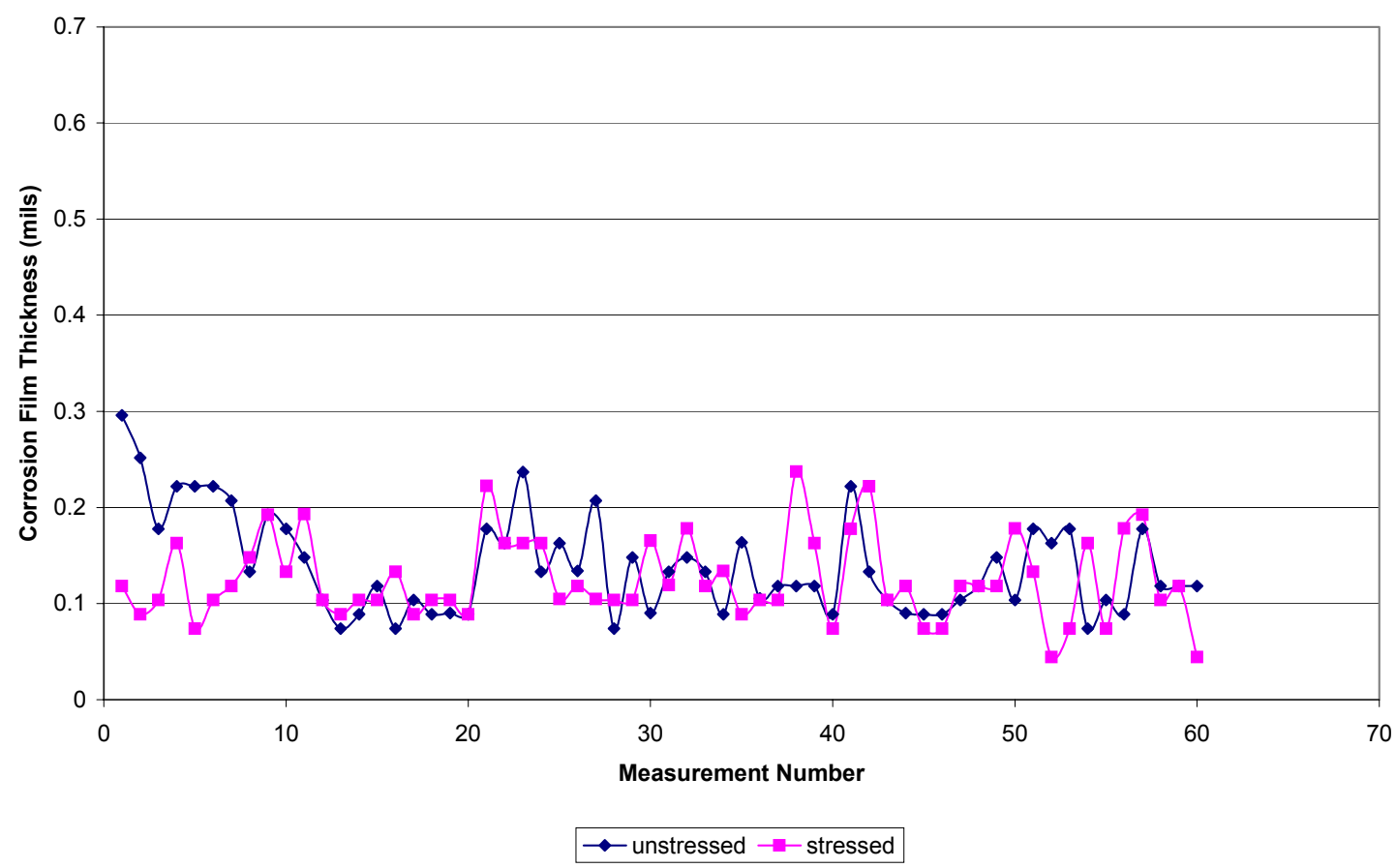


Figure 8

Visual Appearance of Autoclave Sample Gage Sections at End of Test
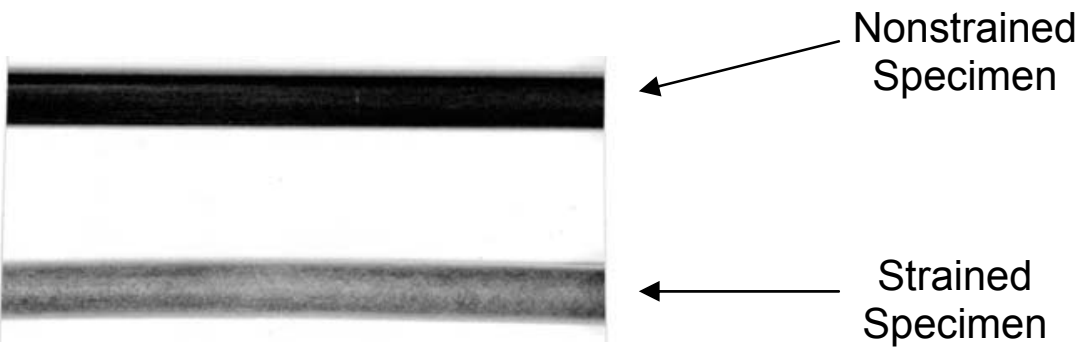

Figure 9

Representative Metallography of Autoclave Samples

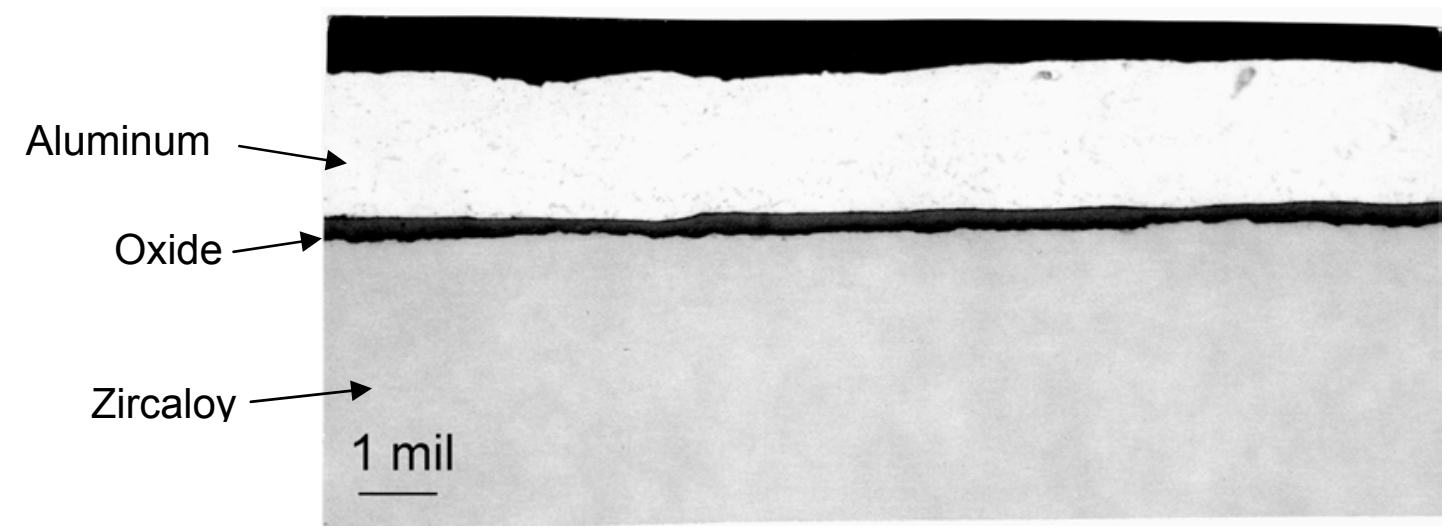

Nonstrained

Specimen

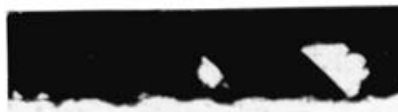

Aluminum $\longrightarrow$

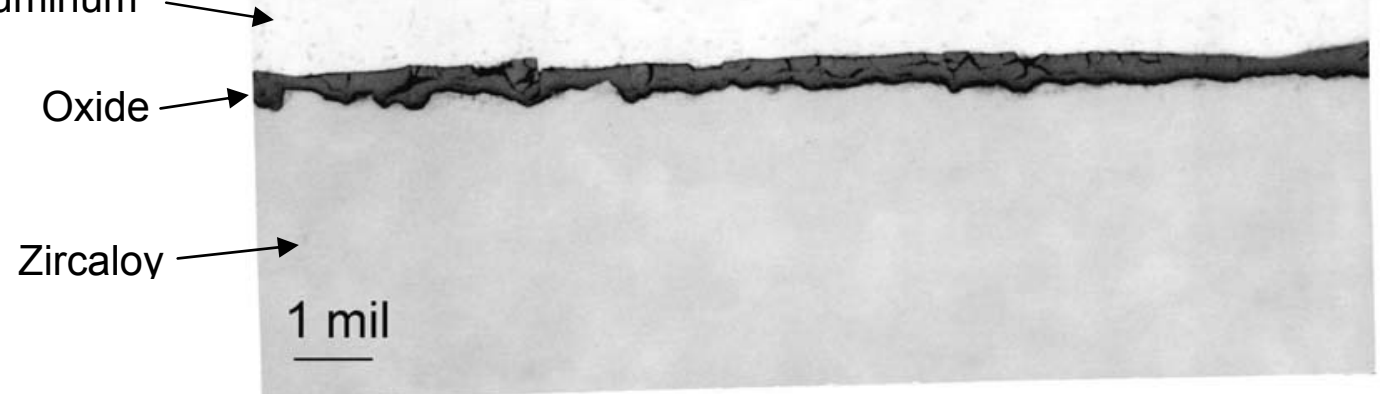

Strained Specimen 
Figure 10

Summary of Metallographic Measurements made on Autoclave Samples

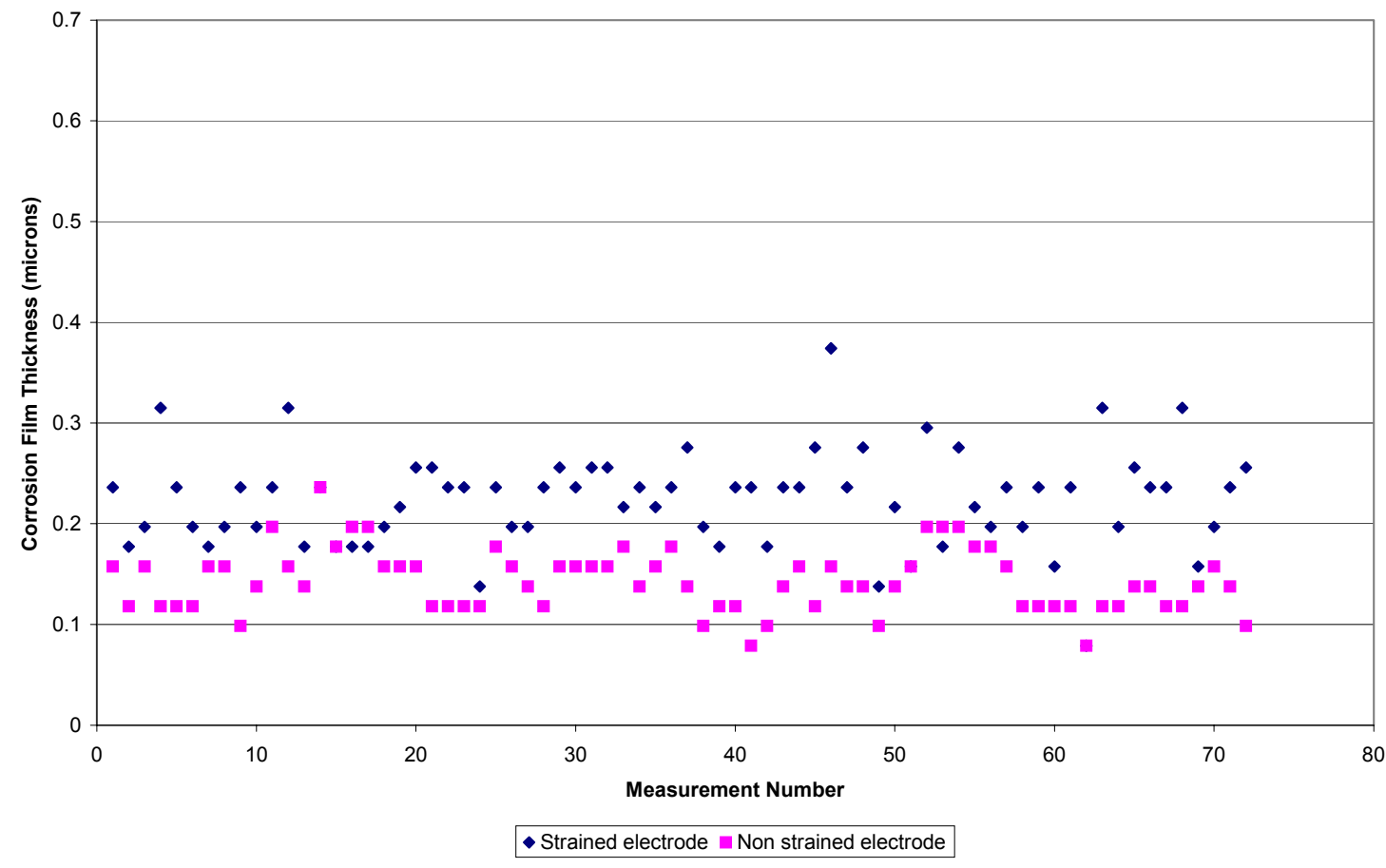


Figure 11A:

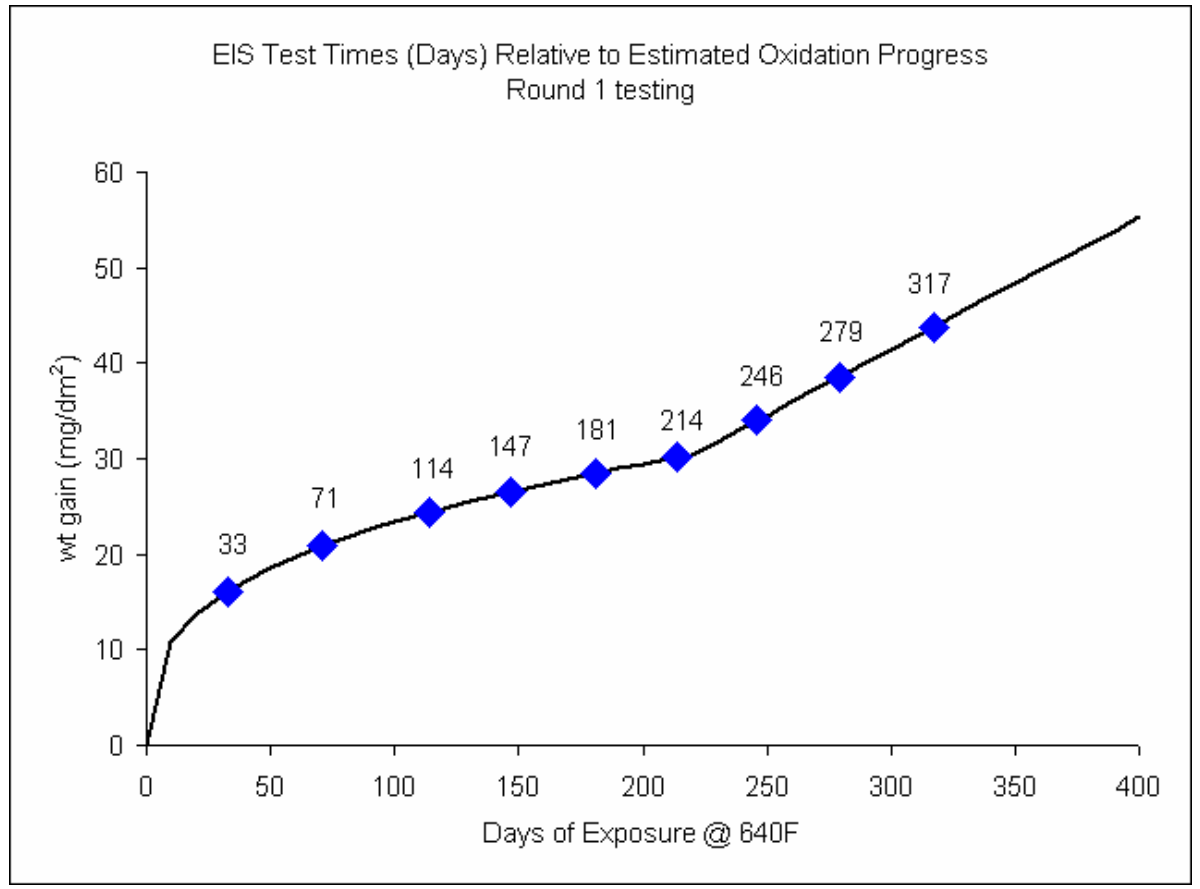

Figure 11B:

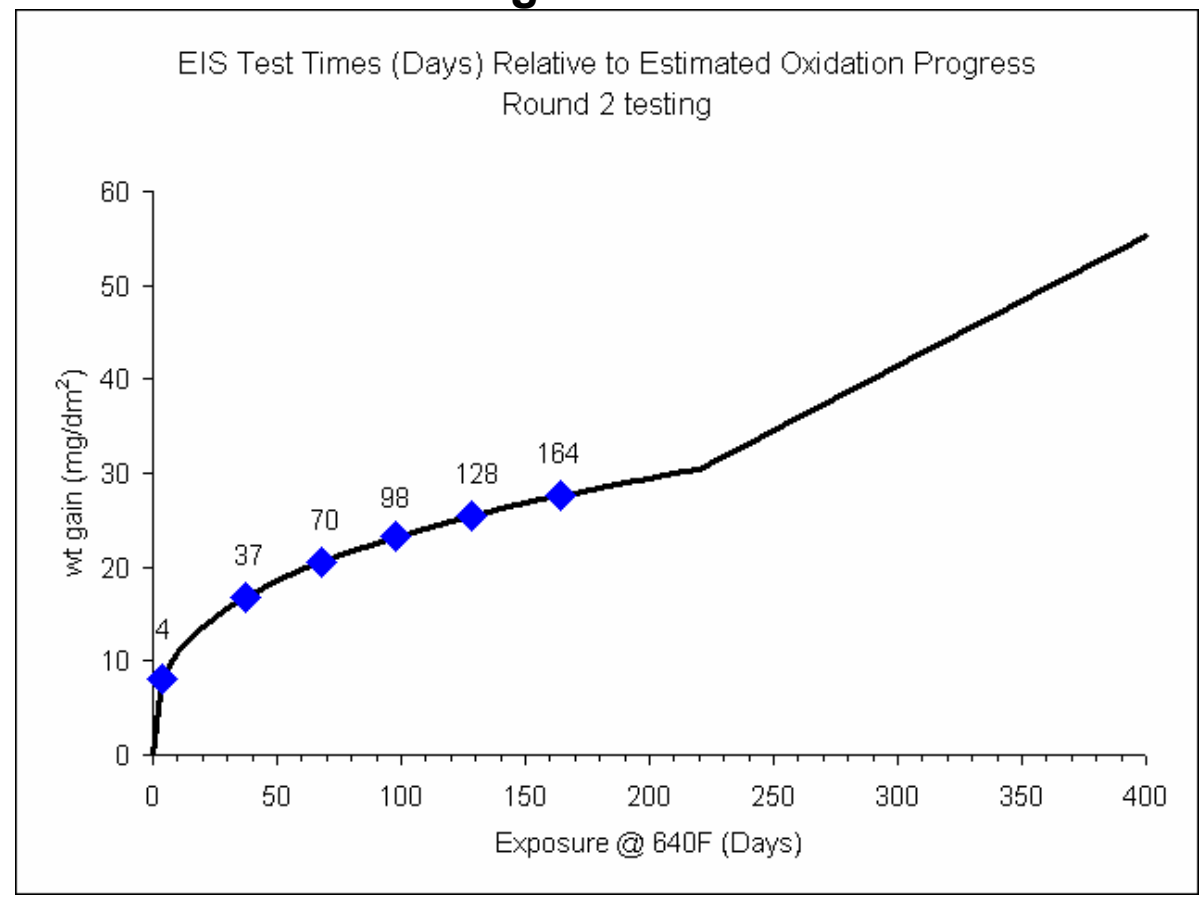


Figure 12A

Impedance Scans of Nonstrained Electrode -Round 1 testing, pretransition
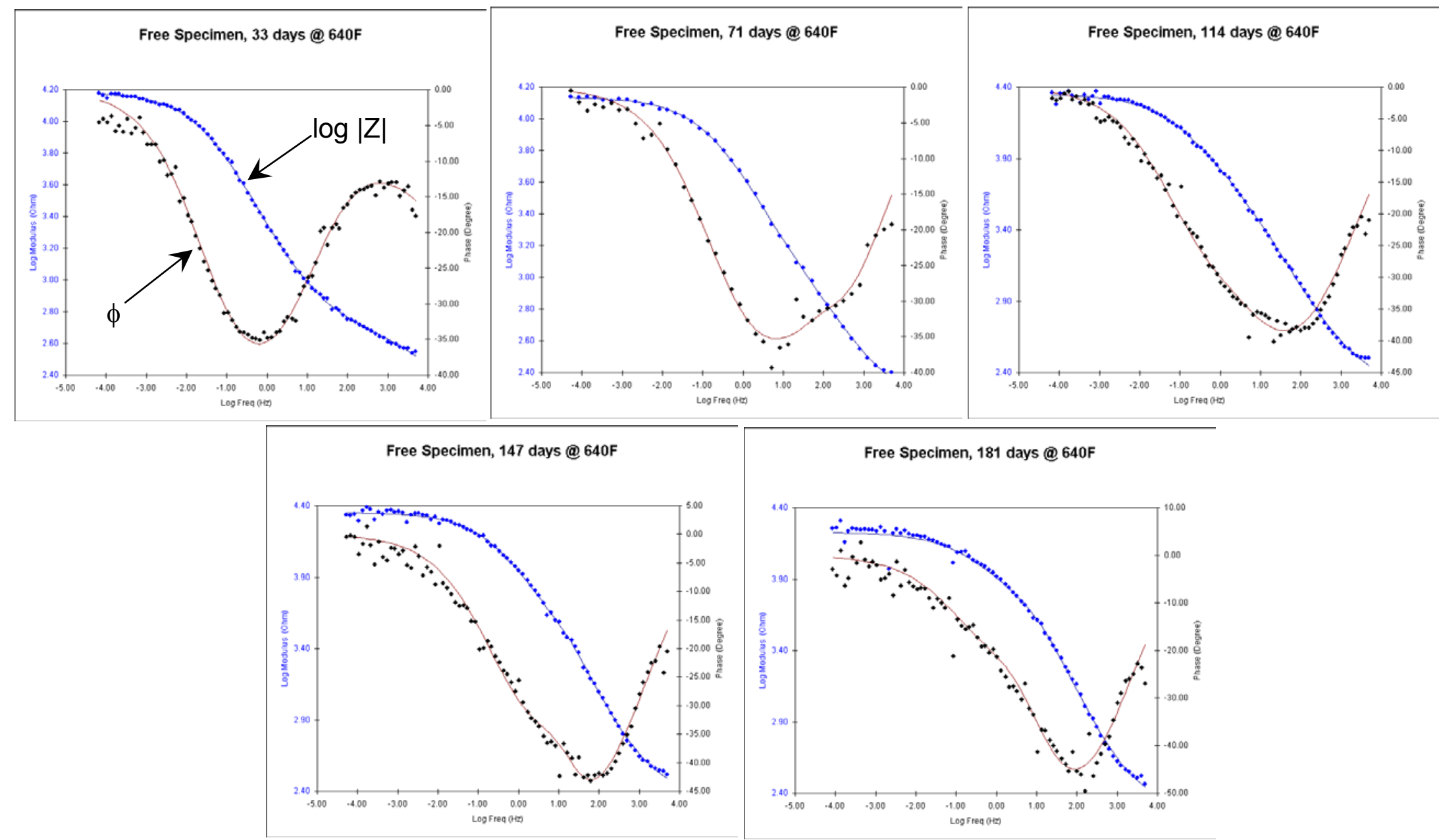
Figure 12B:

Impedance Scans of Nonstrained Electrode -Round 1 testing, posttransition
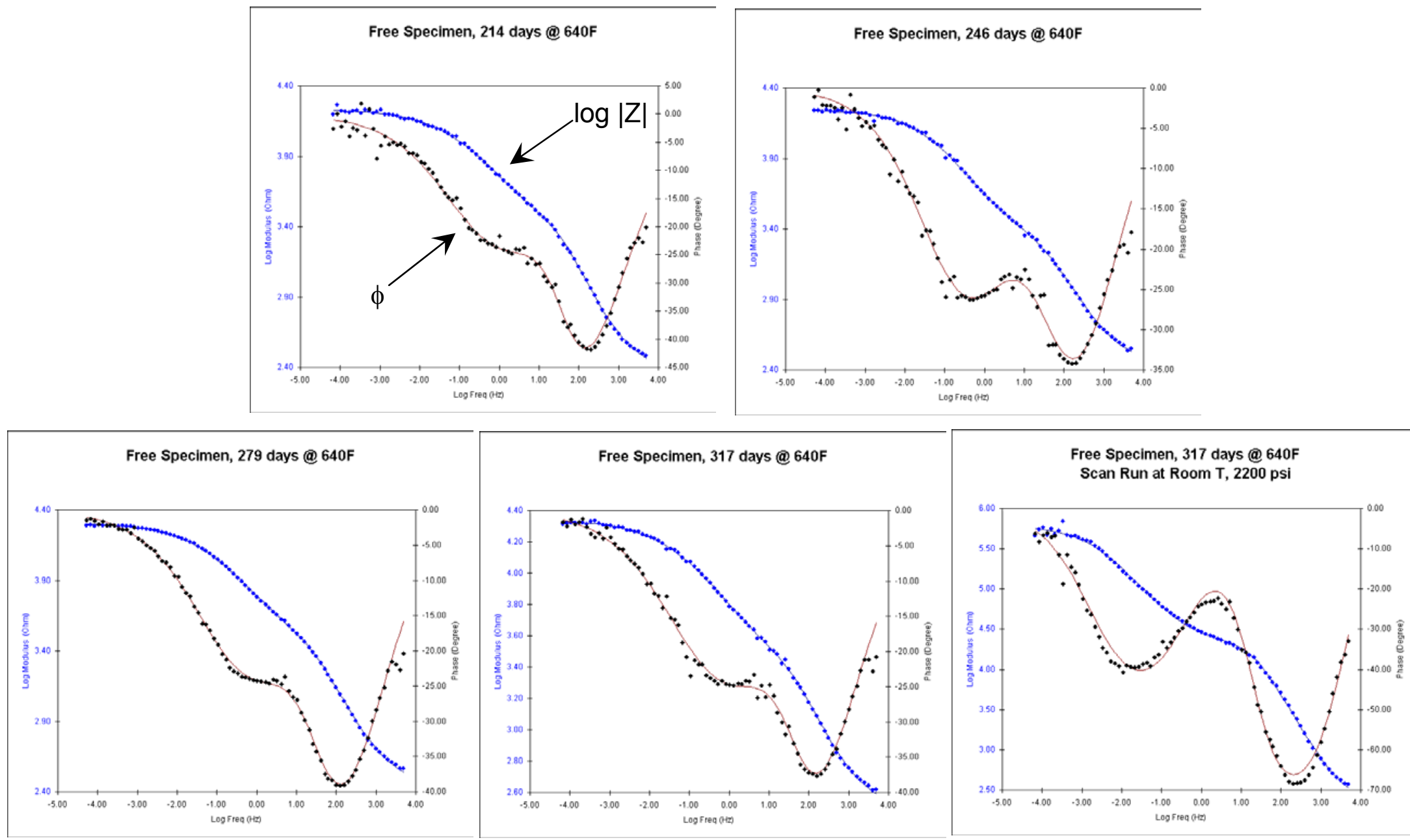
Figure 13: Impedance Scans of Nonstrained Electrode -Round 2 testing, pretransition
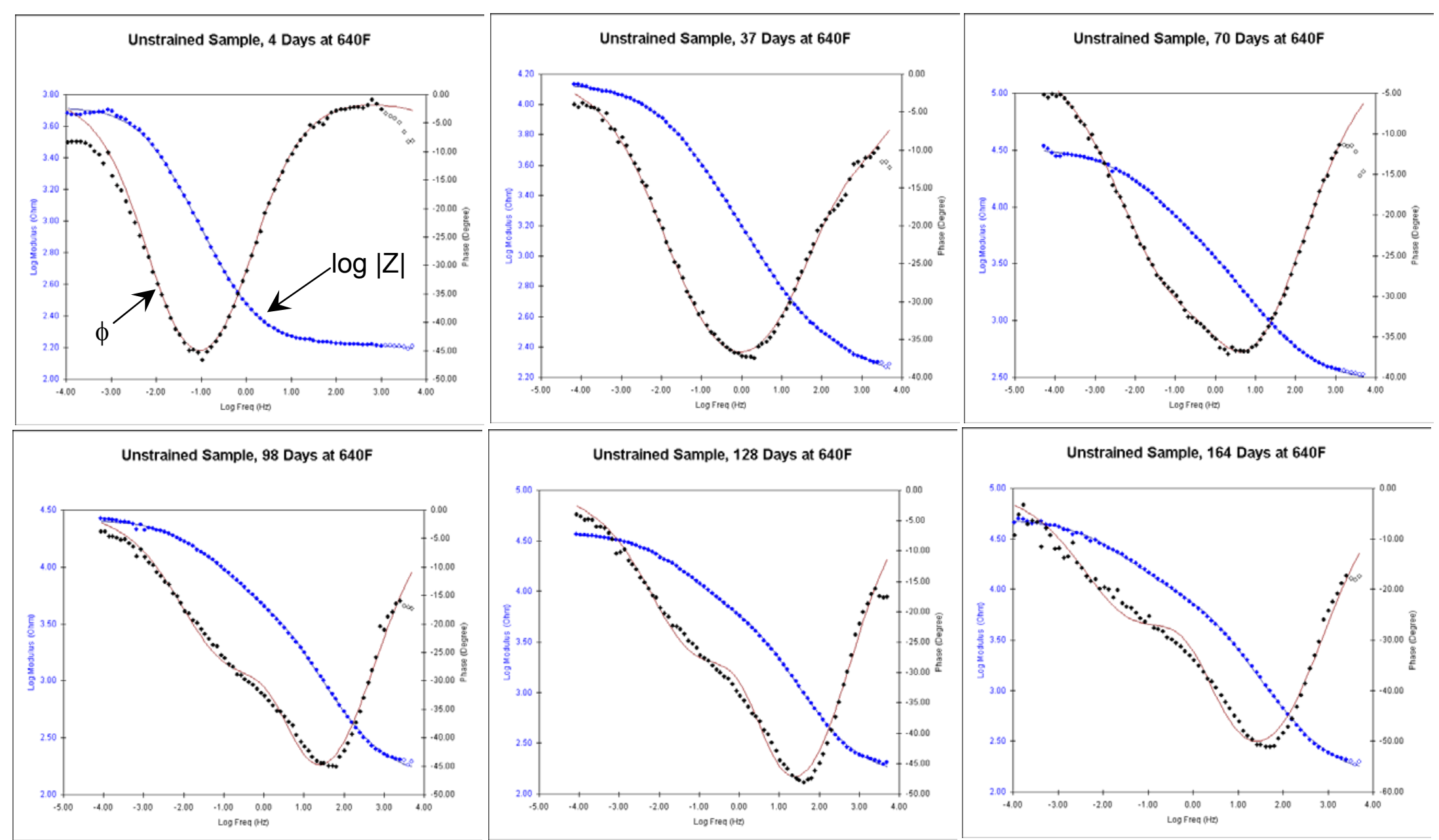
Figure 14: Impedance Scans of Strained Electrode -Round 2 testing, pretransition. Load removed during data collection.
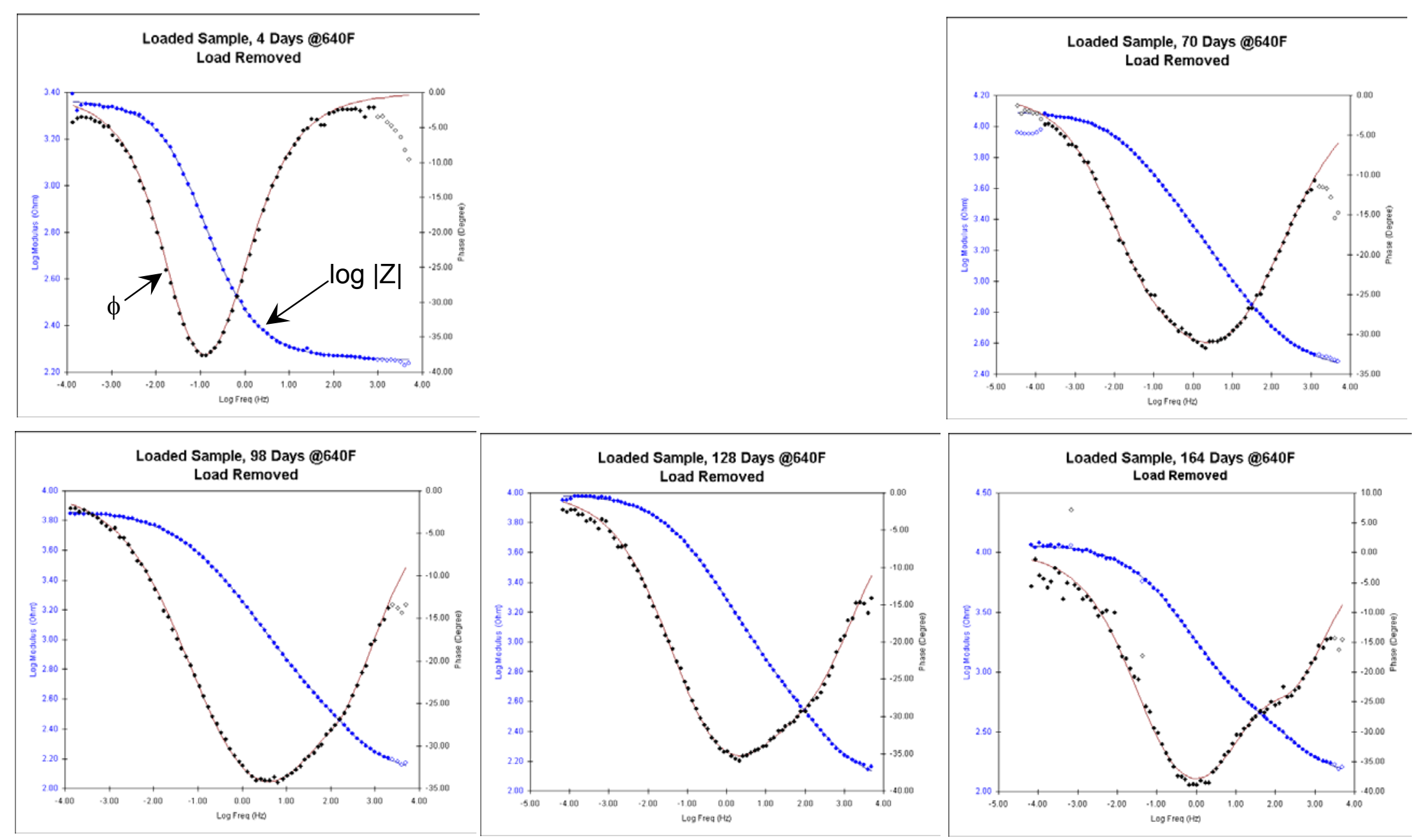
Figure 15: Impedance Scans of Strained Electrode -Round 2 testing, pretransition. Load and/or strain applied during data collection.
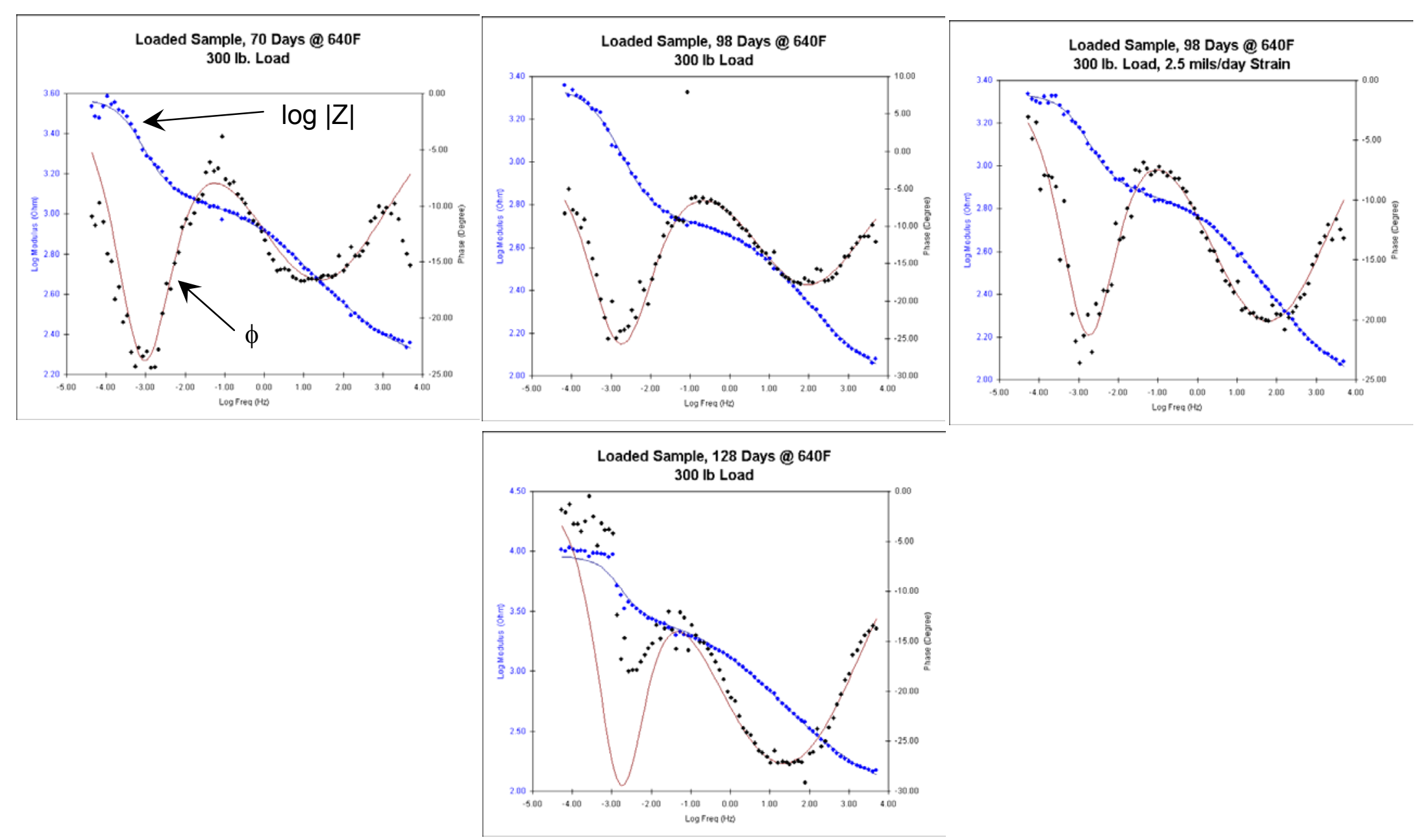
Figure 16

Analogue Circuit and Physical Representation

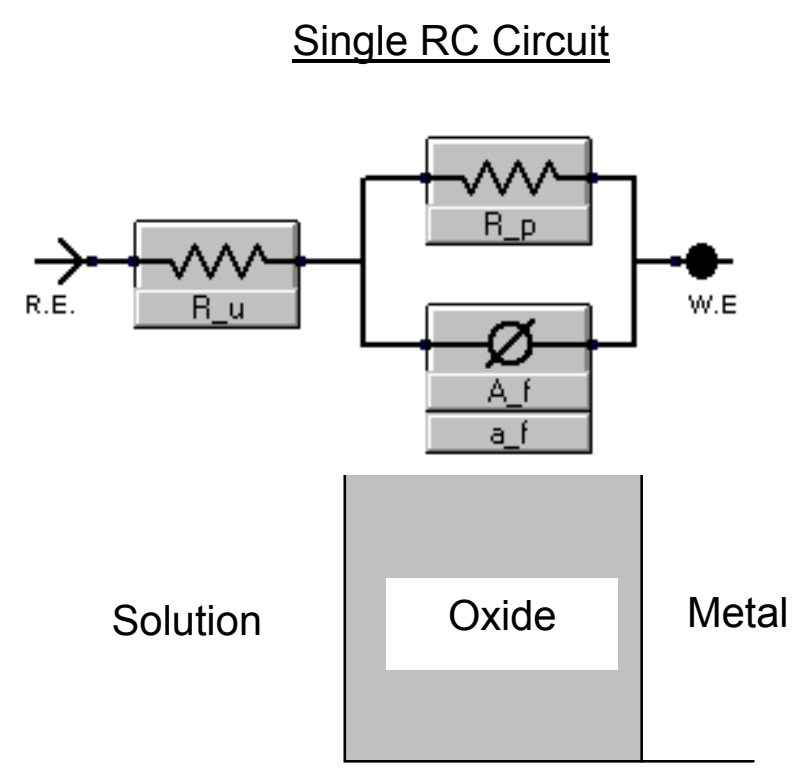

Dual RC Circuit

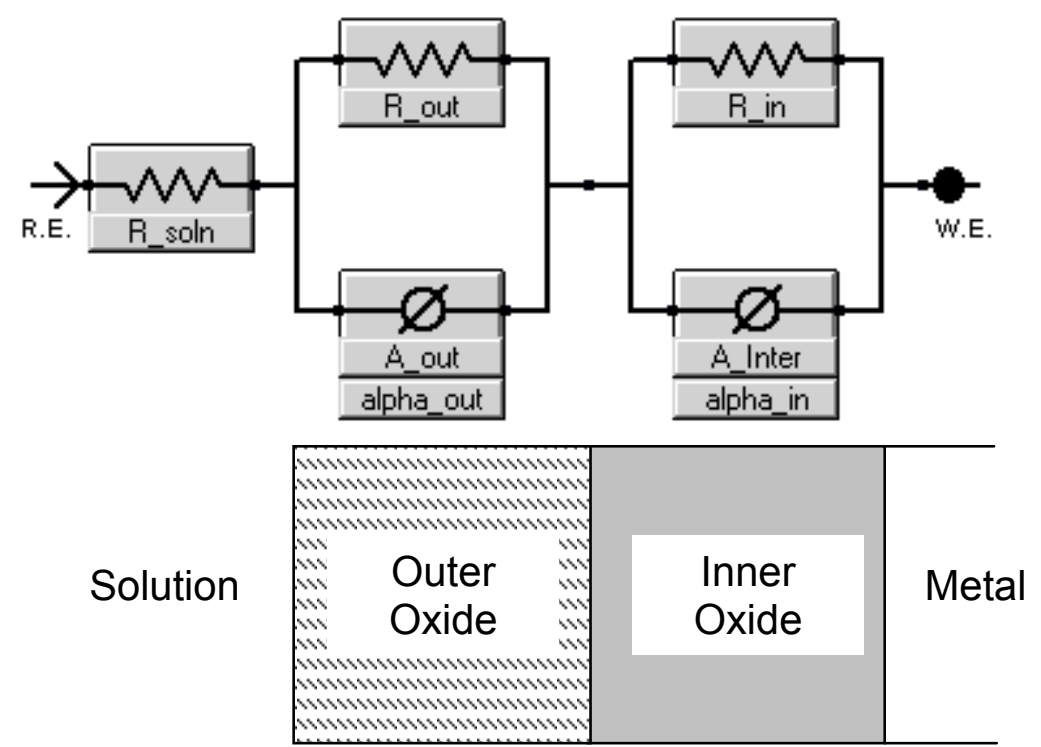




\section{$12 / 11 / 03$}

B-T-3352

Page 42 of 46

Figure 17

Transmission Electron Micrograph of a Pretransition Corrosion Film in Cross Section

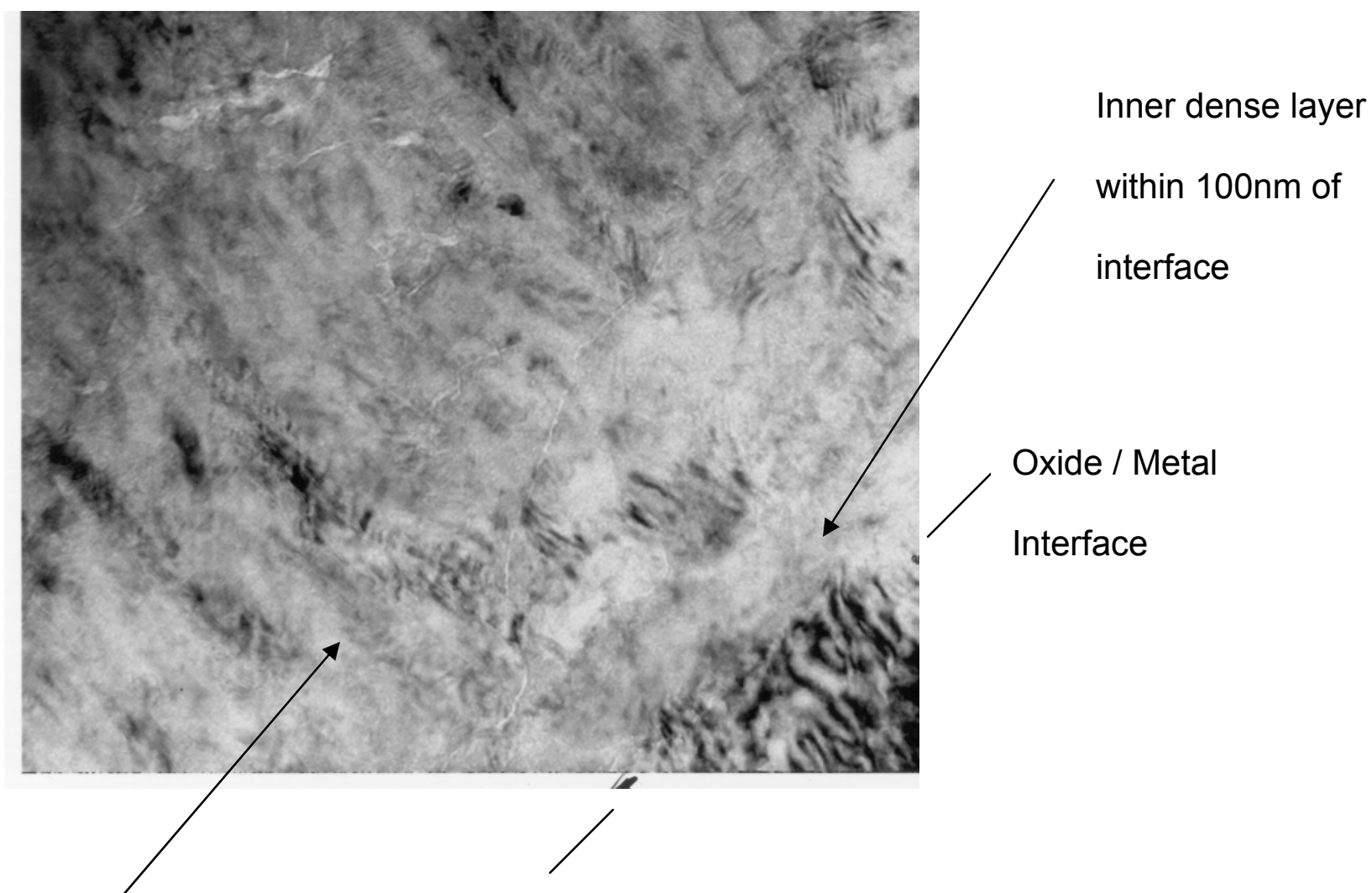

Majority of Pretransition

Oxide / Metal

corrosion film layer with

Interface

columnar oxide grains and

distributed porosity 
Figure 18

Summary of Enhanced Corrosion Vs Applied Strain Rate

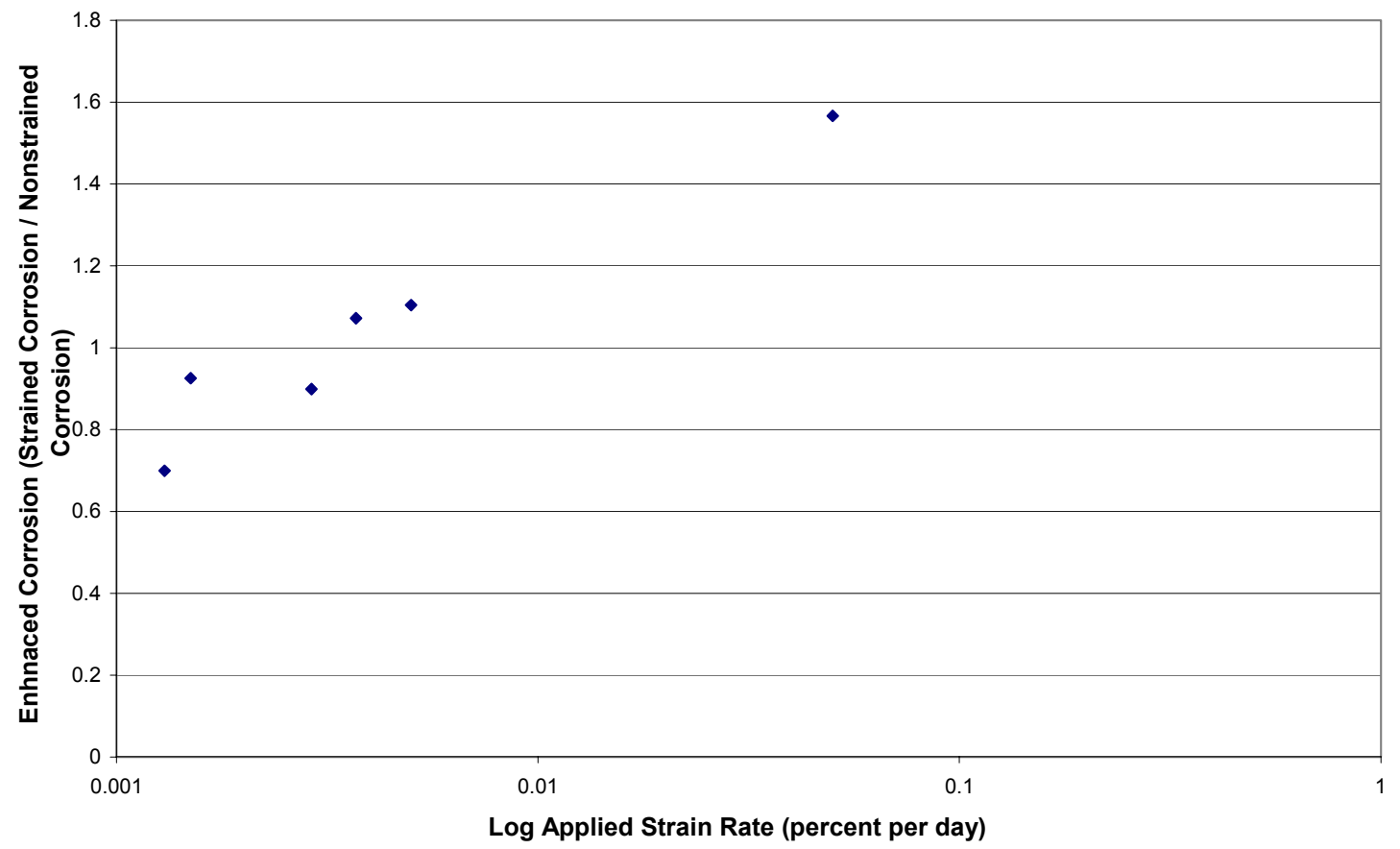


Table 1

Round 1 Testing: Nonstrained Electrode

Evolution of the Dual RC Circuit parameters with Exposure Time at 640F

\begin{tabular}{|c|c|c|c|c|c|c|c|c|c|c|c|c|c|c|c|c|c|c|}
\hline \multirow[b]{3}{*}{$\begin{array}{c}\text { Days at } \\
640 \mathrm{~F}\end{array}$} & \multicolumn{8}{|c|}{ Low Frequency } & \multicolumn{8}{|c|}{ High Frequency } & \multicolumn{2}{|c|}{ Solution } \\
\hline & $\mathrm{R}_{\text {low }}$ & $R_{\text {low }}$ & $A_{\text {low }}$ & $A_{\text {low }}$ & $\mathrm{C}_{\text {low }}$ & $\mathrm{C}_{\text {low }}$ & $\alpha_{\text {low }}$ & $\alpha_{\text {low }}$ & $R_{\text {high }}$ & $\mathrm{R}_{\text {high }}$ & $A_{\text {high }}$ & $A_{\text {high }}$ & $\mathrm{C}_{\text {high }}$ & $\mathrm{C}_{\text {high }}$ & $\alpha_{\text {high }}$ & $\alpha_{\text {high }}$ & $\mathrm{R}_{\text {solution }}$ & error \\
\hline & $(\mathrm{Ohm})$ & error & $(1 / F)$ & error & $(\mu-F)$ & error & & error & (Ohm) & error & $(1 / F)$ & error & $(\mu-F)$ & error & & error & (Ohm) & \\
\hline 33 & 14720 & 189 & 5653 & 96 & 177 & 3 & 0.55 & 0.008 & 527 & 361 & 29810 & 16500 & 34 & 19 & 0.36 & 0.17 & $0 . E+00$ & 307 \\
\hline 71 & 13360 & 234 & 13710 & 345 & 73 & 2 & 0.52 & 0.01 & 185 & 107 & 26560 & 30040 & 38 & 43 & 0.69 & 0.17 & 172 & 11 \\
\hline 114 & 19550 & 2921 & 14650 & 4754 & 68 & 22 & 0.52 & 0.04 & 2647 & 2715 & 15370 & 4391 & 65 & 19 & 0.57 & 0.07 & 196 & 7 \\
\hline 147 & 21500 & 340 & 28830 & 1210 & 35 & 1 & 0.54 & 0.007 & 867 & 282 & 74160 & 28910 & 13 & 5 & 0.9 & 0.1 & 220 & 10 \\
\hline 167 & 12480 & 1226 & 15170 & 3426 & 66 & 15 & 0.53 & 0.02 & 4227 & 1167 & 78280 & 7417 & 13 & 1 & 0.72 & 0.05 & 199 & 12 \\
\hline 214 & 15480 & 340 & 13180 & 606 & 76 & 3 & 0.48 & 0.01 & 1468 & 217 & 156100 & 31190 & 6 & 1 & 0.84 & 0.05 & 201 & 12 \\
\hline 246 & 15580 & 296 & 8552 & 323 & 117 & 4 & 0.54 & 0.01 & 1736 & 161 & 70820 & 9105 & 14 & 2 & 0.67 & 0.02 & 271 & 8 \\
\hline 279 & 18170 & 501 & 12920 & 766 & 77 & 5 & 0.48 & 0.02 & 1867 & 329 & 104000 & 18260 & 10 & 2 & 0.76 & 0.04 & 257 & 12 \\
\hline 317 & 20150 & 488 & 13690 & 638 & 73 & 3 & 0.47 & 0.01 & 1572 & 275 & 126100 & 26360 & 8 & 2 & 0.78 & 0.05 & 282 & 13 \\
\hline 317 & 577500 & 8543 & 36640 & 626 & 27 & 0 & 0.62 & 0.006 & 19560 & 394 & 1333000 & 54950 & 0.8 & 0.03 & 0.89 & 0.01 & 232 & 7 \\
\hline
\end{tabular}

*: EIS spectra obtained with the autoclave at room temperature and $2200 \mathrm{psi}$. 
Table 2

Round 2 Testing: Nonstrained Electrode

Evolution of the Dual RC Circuit parameters with Exposure Time at 640F

\begin{tabular}{|c|c|c|c|c|c|c|c|c|c|c|c|c|c|c|c|c|c|c|}
\hline \multirow[b]{2}{*}{$\begin{array}{c}\text { approx } \\
\text { Days at } \\
640 \mathrm{~F}\end{array}$} & \multicolumn{8}{|c|}{ Low Frequency } & \multicolumn{8}{|c|}{ High Frequency } & \multicolumn{2}{|c|}{ Solution } \\
\hline & $\begin{array}{c}\mathrm{R}_{\text {low }} \\
(\mathrm{Ohm}) \\
\end{array}$ & $\begin{array}{l}R_{\text {low }} \\
\text { error }\end{array}$ & $\begin{array}{l}A_{\text {low }} \\
(1 / F)\end{array}$ & $\begin{array}{l}A_{\text {low }} \\
\text { error }\end{array}$ & $\begin{array}{l}\mathrm{C}_{\text {low }} \\
(\mu-\mathrm{F})\end{array}$ & $\begin{array}{l}\mathrm{C}_{\text {low }} \\
\text { error }\end{array}$ & $\alpha_{\text {low }}$ & $\begin{array}{l}\alpha_{\text {low }} \\
\text { error }\end{array}$ & $\begin{array}{l}R_{\text {high }} \\
(\mathrm{Ohm}) \\
\end{array}$ & $\begin{array}{l}\mathrm{R}_{\text {high }} \\
\text { error }\end{array}$ & $\begin{array}{l}A_{\text {high }} \\
(1 / F)\end{array}$ & $\begin{array}{l}A_{\text {high }} \\
\text { error }\end{array}$ & $\begin{array}{l}\mathrm{C}_{\text {high }} \\
(\mu-\mathrm{F})\end{array}$ & $\begin{array}{l}\mathrm{C}_{\text {high }} \\
\text { error }\end{array}$ & $\alpha_{\text {nigh }}$ & $\begin{array}{l}\alpha_{\text {high }} \\
\text { error }\end{array}$ & $\begin{array}{l}R_{\text {solution }} \\
(\mathrm{Ohm}) \\
\end{array}$ & error \\
\hline 4 & 5132 & 60 & 634 & 9 & 1577 & 22 & 0.68 & 0.006 & 167 & 15490 & 147200 & $2.50 \mathrm{E}+07$ & 7 & 1154 & 0.4 & 1.5 & 0 & 15480 \\
\hline 37 & 13600 & 166 & 3936 & 41 & 254 & 3 & 0.51 & 0.005 & 38 & 35 & 15660 & 42670 & 64 & 174 & 0.66 & 0.45 & 157 & 25 \\
\hline 70 & 32340 & 479 & 7404 & 295 & 135 & 5 & 0.47 & 0.005 & 682 & 284 & 4477 & 1086 & 223 & 54 & 0.81 & 0.13 & 276 & 6 \\
\hline 98 & 23760 & 758 & 7308 & 648 & 137 & 12 & 0.53 & 0.02 & 2436 & 510 & 22280 & 1786 & 45 & 4 & 0.73 & 0.04 & 147 & 6 \\
\hline 128 & 33850 & 870 & 8384 & 608 & 119 & 9 & 0.53 & 0.01 & 3615 & 536 & 29770 & 1975 & 34 & 2 & 0.74 & 0.03 & 157 & 5 \\
\hline
\end{tabular}

Table 3

Round 2 Testing: Strained Electrode

Evolution of the Dual RC Circuit parameters with Exposure Time at 640F

\begin{tabular}{|c|c|c|c|c|c|c|c|c|c|c|c|c|c|c|c|c|c|c|}
\hline \multirow[b]{2}{*}{$\begin{array}{c}\text { Days at } \\
640 \mathrm{~F}\end{array}$} & \multicolumn{8}{|c|}{ Low Frequency } & \multicolumn{8}{|c|}{ High Frequency } & \multicolumn{2}{|c|}{ Solution } \\
\hline & $\begin{array}{c}\mathrm{R}_{\text {low }} \\
(\mathrm{Ohm})\end{array}$ & $\begin{array}{l}R_{\text {low }} \\
\text { error }\end{array}$ & $\begin{array}{l}A_{\text {low }} \\
(1 / F)\end{array}$ & $\begin{array}{l}A_{\text {low }} \\
\text { error }\end{array}$ & $\begin{array}{l}\mathrm{C}_{\text {low }} \\
(\mu-\mathrm{F})\end{array}$ & $\begin{array}{l}\mathrm{C}_{\text {low }} \\
\text { error }\end{array}$ & $\alpha_{\text {low }}$ & error & $\begin{array}{l}R_{\text {high }} \\
(\mathrm{Ohm})\end{array}$ & $\begin{array}{l}R_{\text {high }} \\
\text { error }\end{array}$ & $\begin{array}{l}A_{\text {high }} \\
(1 / F)\end{array}$ & $\begin{array}{l}A_{\text {high }} \\
\text { error }\end{array}$ & $\begin{array}{l}C_{\text {high }} \\
(\mu-F)\end{array}$ & $\begin{array}{l}\mathrm{C}_{\text {high }} \\
\text { error }\end{array}$ & $\alpha_{\text {high }}$ & $\begin{array}{l}\alpha_{\text {high }} \\
\text { error }\end{array}$ & $\begin{array}{c}\mathrm{R}_{\text {solution }} \\
(\mathrm{Ohm}) \\
\end{array}$ & error \\
\hline $4^{*}$ & 1756 & 228 & 443 & 80 & 2257 & 408 & 0.75 & 0.04 & 447 & 287 & 113 & 81 & 8850 & 6343 & 0.4 & 0.1 & 178 & 0 \\
\hline 37 & 13600 & 162 & 3938 & 39 & 254 & 3 & 0.51 & 0.01 & 30.5 & 21 & 28350 & 74050 & 35 & 92 & 0.8 & 0.41 & 163 & 14 \\
\hline 70 & 8848 & 3643 & 2523 & 1952 & 396 & 307 & 0.56 & 0.07 & 3328 & 3510 & 4281 & 1458 & 234 & 80 & 0.45 & 0.02 & 261 & 11 \\
\hline $70^{\star \star}$ & 2525 & 77 & 21 & 3 & 47619 & 6803 & 0.81 & 0.02 & 1076 & 33 & 2943 & 155 & 340 & 18 & 0.39 & 0.01 & 173 & 6 \\
\hline 98 & 7205 & 99 & 5131 & 80 & 195 & 3 & 0.49 & 0.009 & 41 & 27 & 14580 & 21850 & 69 & 103 & 0.87 & 0.25 & 119 & 4 \\
\hline $98^{* \star}$ & 1700 & 47 & 30 & 3 & 33333 & 3333 & 0.74 & 0.02 & 449 & 11 & 3349 & 238 & 299 & 21 & 0.45 & 0.01 & 90 & 3 \\
\hline $98^{\star \star \star}$ & 1389 & 41 & 22 & 3 & 45455 & 6198 & 0.8 & 0.02 & 699 & 17 & 3096 & 168 & 323 & 18 & 0.43 & 0.01 & 88 & 3 \\
\hline 128 & 9459 & 161 & 5168 & 150 & 193 & 6 & 0.52 & 0.01 & 172 & 83 & 4382 & 2433 & 228 & 127 & 0.55 & 0.01 & 109 & 5 \\
\hline $128^{\star *}$ & 2444 & 2445 & 1848 & 1521 & 541 & 445 & 0.7 & 0.15 & 7800 & 2327 & 3847 & 1530 & 260 & 103 & 0.42 & 0.04 & 91 & 10 \\
\hline
\end{tabular}

* Rsoln had to be set in order to obtain any reasonable fit.

* Load applied during EIS acquisition

** Load and active strain applied during EIS acquisition. 
Table 4

Round 2 Testing: Nonstrained Electrode

Evolution of the Single RC Circuit parameters with Exposure Time at 640F

\begin{tabular}{|c|c|c|c|c|c|c|c|c|c|c|}
\cline { 2 - 11 } \multicolumn{1}{c|}{} & \multicolumn{9}{c|}{ Low Frequency } & \multicolumn{2}{c|}{ Solution } \\
\cline { 2 - 11 } & $\mathrm{R}_{\text {low }}$ & $\mathrm{R}_{\text {low }}$ & $\mathrm{A}_{\text {low }}$ & $\mathrm{A}_{\text {low }}$ & $\mathrm{C}_{\text {low }}$ & $\mathrm{C}_{\text {low }}$ & $\alpha_{\text {low }}$ & $\alpha_{\text {low }}$ & $\mathrm{R}_{\text {solution }}$ & error \\
$\begin{array}{c}\text { Days at } \\
\mathbf{6 4 0 F}\end{array}$ & $(\mathrm{Ohm})$ & error & $(1 / \mathrm{F})$ & error & $(\mu-\mathrm{F})$ & error & & error & $(\mathrm{Ohm})$ & \\
\hline $\mathbf{4}$ & 5149 & 44 & 638 & 5 & 1567 & 12 & 0.68 & 0.004 & 165 & 1 \\
\hline $\mathbf{3 7}$ & 13880 & 122 & 3942 & 29 & 254 & 2 & 0.49 & 0.002 & 173 & 2 \\
\hline $\mathbf{7 0}$ & 32480 & 299 & 8347 & 59 & 120 & 1 & 0.47 & 0.002 & 247 & 5 \\
\hline 128 & 24900 & 191 & 12120 & 103 & 83 & 1 & 0.5 & 0.002 & 107 & 2 \\
\cline { 2 - 11 }
\end{tabular}

Table 5

Round 2 Testing: Strained Electrode

Evolution of the Single RC Circuit parameters with Exposure Time at 640F

\begin{tabular}{|c|c|c|c|c|c|c|c|c|c|c|}
\cline { 2 - 11 } \multicolumn{1}{c|}{} & \multicolumn{9}{c|}{ Low Frequency } & \multicolumn{2}{c|}{ Solution } \\
\cline { 2 - 11 } & $\mathrm{R}_{\text {low }}$ & $\mathrm{R}_{\text {low }}$ & $\mathrm{A}_{\text {low }}$ & $\mathrm{A}_{\text {low }}$ & $\mathrm{C}_{\text {low }}$ & $\mathrm{C}_{\text {low }}$ & $\alpha_{\text {low }}$ & $\alpha_{\text {low }}$ & $\mathrm{R}_{\text {solution }}$ & error \\
$\mathbf{6 4 0 \mathrm { F }}$ & $(\mathrm{Ohm})$ & error & $(1 / \mathrm{F})$ & error & $(\mu-\mathrm{F})$ & error & & error & $(\mathrm{Ohm})$ & \\
\hline 4 & 2131 & 18 & 555 & 6 & 1802 & 19 & 0.68 & 0.005 & 184 & 12 \\
\hline 37 & 13810 & 121 & 3947 & 30 & 253 & 2 & 0.5 & 0.002 & 177 & 2 \\
\hline 70 & 12850 & 133 & 5533 & 51 & 181 & 2 & 0.45 & 0.003 & 255 & 5 \\
\hline 128 & 7371 & 59 & 5142 & 54 & 194 & 2 & 0.48 & 0.003 & 114 & 2 \\
\hline
\end{tabular}

